\title{
Hydrogen production from cheese whey by catalytic steam reforming: Preliminary study using lactose as a model compound
}

\author{
J. Remón, M. Laseca, L. García*, J. Arauzo
}

Thermochemical Processes Group (GPT), Aragón Institute for Engineering Research (I3A), Universidad de Zaragoza. Mariano Esquillor s/n, E-50018 Zaragoza, Spain. *Corresponding author. Tel: +34 976 762194; Fax.: +34 976 761879; e-mail: luciag@unizar.es

\section{ABSTRACT}

Cheese whey is a yellowish liquid by-product of the cheese making process. Owing to its high BOD and COD values, this feedstock should not be directly discharged into the environment without appropriate treatment. Before dealing with real cheese whey, this work addresses the production of a rich hydrogen gas from lactose (the largest organic constituent of this waste) by catalytic steam reforming. This reforming process has been theoretically and experimentally studied. The theoretical study examines the effect of the temperature $\left(300-600{ }^{\circ} \mathrm{C}\right)$, lactose concentration $(1-10 \mathrm{wt} . \%)$ and $\mathrm{N}_{2}\left(0-80 \mathrm{~cm}^{3}\right.$ $\mathrm{STP} / \mathrm{min})$ and liquid flow $(0.1-0.5 \mathrm{~mL} / \mathrm{min})$ rates on the thermodynamic composition of the gas. The results show that the temperature and lactose concentration exerted the greatest influence on the thermodynamics. The experimental study, conducted in a fixed bed reactor using a Ni-based catalyst, considers the effect of the temperature (300-600 $\left.{ }^{\circ} \mathrm{C}\right)$, lactose concentration (1-10 wt.\%) and spatial time (4-16 g catalyst min/ g lactose) on the global lactose conversion, product distribution on a carbon basis (gas, liquid and solid) and the compositions of the gas and liquid phases. Complete lactose conversion was achieved under all the experimental conditions. The carbon converted into gas, liquid and solid was $2-97 \%, 0-66 \%$ and $0-94 \%$, respectively. The gas phase was made up of a mixture of $\mathrm{H}_{2}\left(0-70\right.$ vol.\%), $\mathrm{CO}_{2}\left(20-70\right.$ vol.\%), $\mathrm{CO}\left(2-34\right.$ vol.\%) and $\mathrm{CH}_{4}(0-3$ vol.\%). The liquid phase consisted of a mixture of aldehydes, ketones, carboxylic acids, sugars, furans, alcohols and phenols. Optimal conditions for cheese whey valorisation 
1 were sought considering the energetic aspects of the process. Using a lactose

2 concentration similar to that of cheese whey (5.5 wt.\%), maxima for the CC gas ( $88 \%)$

3 and the proportion of $\mathrm{H}_{2}(67 \mathrm{vol} . \%)$ in the gas together with a carbon-free liquid stream

4 can be achieved at $586{ }^{\circ} \mathrm{C}$ using a spatial time of $16 \mathrm{~g}$ catalyst min/g lactose.

5 Theoretically, the combustion of $20 \%$ of this gas provides the energy necessary for the

6 process enabling the transformation of $68 \%$ of the carbon present in the initial effluent

7 into a $\mathrm{H}_{2}$ rich gas $\left(67\right.$ vol.\%) with a global $\mathrm{H}_{2}$ yield of $16 \mathrm{~mol} \mathrm{H}_{2} / \mathrm{mol}$ lactose. In a real

8 case it would be necessary to increase the amount of gas combusted to compensate for

9 heat losses.

11 Keywords: cheese whey, lactose, catalytic steam reforming, hydrogen production 


\section{Introduction}

2 Cheese whey is a yellowish liquid resulting from the coprecipitation and removal of

3 milk casein in cheese making processes. On average, for the production of $1 \mathrm{~kg}$ of

4 cheese $10 \mathrm{~kg}$ of milk are used, which produces $9 \mathrm{~kg}$ of cheese whey as a by-product.

5 This is equivalent to 5 million tons a year of whey worldwide. Some of the most

6 important components of whey are lactose and soluble proteins. Typically, cheese whey

7 contains $4.5-6$ wt. $\%$ lactose, $0.6-1.1$ wt. $\%$ proteins, $0.8-1$ wt. $\%$ minerals, $0.05-0.9$ wt.\%

8 lactic acid, 0.06-0.5 wt.\% fats and 93-94 wt.\% of water [1-4]. This effluent produced by

9 the cheese industry has BOD and COD values ranging from $27-60 \mathrm{~kg} / \mathrm{m}^{3}$ and $50-102$

$10 \mathrm{~kg} / \mathrm{m}^{3}$, respectively. Therefore, it should not be directly discharged into the environment

11 without appropriate treatment and/or valorisation [3]. In the past, most cheese factories

12 released their effluents onto land or discharged them into rivers, lakes and/or oceans

13 without any pre-treatment. However, as a result of environmental concerns and stricter

14 regulations, cheese effluent management has become an important issue [1-4].

16 In this context, two different options for cheese whey management have normally been

17 considered [3]. The first is the application of filtration technologies and 18 physicochemical treatments such as coagulation-flocculation. These technologies aim to 19 recover the most valuable compounds from cheese whey such as proteins and lactose.

20 Filtration technologies can be used to separate lactose and proteins from whey [3].

21 Ultrafiltration membranes can be used to separate proteins and reverse osmosis to

22 increase the lactose concentration in order to facilitate the evaporation of water and the

23 crystallisation of lactose [2]. Physicochemical treatments include thermal and isoelectric

24 precipitation [5, 6], as well as protein precipitation with coagulant/ flocculant agents [7]. 
2 The second option relies on the application of biological treatments without

3 valorisation, such as aerobic digestion, and with valorisation such as anaerobic

4 digestion, lactose hydrolysis and fermentation for hydrogen and methane production

5 [3]. Aerobic digestion consists of the degradation of the organic matter of whey at room

6 temperature using short hydraulic retention times. However, the high organic content of

7 cheese whey makes this technique inappropriate [8]. Anaerobic digestion takes place

8 under mesophilic conditions $\left(35-37^{\circ} \mathrm{C}\right)$ where lactose can be converted into propionic

9 acid, ethanol and lactose acetates [9]. Lactose hydrolysis constitutes a preliminary step

10 for other biological processes, as the number of microorganisms able to metabolise

11 glucose and galactose are significantly higher than those that directly metabolise lactose

$12[4]$.

14 Cheese whey fermentation includes the production of ethanol, lactic acid, and hydrogen.

15 The bioconversion of lactose to ethanol has a theoretical maximum yield of $0.538 \mathrm{~kg}$ 16 ethanol/ $\mathrm{kg}$ of lactose $[10,11]$. However, cheese whey fermentation is hardly 17 economically competitive if compared to other feedstocks, particularly when using 18 diluted cheese whey solutions [3]. To improve the economy of the process, the 19 anaerobic fermentation of the permeate solution obtained after subjecting cheese whey 20 to an ultrafiltration process has been considered, increasing the concentration of the 21 ethanol produced by up to $12 \%$ [11]. The production of lactic acid has usually been 22 carried out using the concentrated cheese whey coming from ultrafiltration [12-16]. The 23 greatest limitation for the production of lactic acid from cheese whey is the low yield of 24 the process $\left(3.8-12 \mathrm{~kg} / \mathrm{m}^{3}\right)$. 
1 Anaerobic fermentation processes have been conducted for hydrogen production from

2 different cheese whey effluents: the original cheese whey [17, 18], diluted cheese whey

3 solutions [19-21], concentrated whey powder [22-24] and permeates resulting from

4 different filtration processes [25]. The anaerobic fermentation has a theoretical yield of

$54 \mathrm{~mol} \mathrm{H}_{2} /$ mol lactose and produces a gas made up of a mixture of $\mathrm{H}_{2}, \mathrm{CO}_{2}$ and $\mathrm{CH}_{4}$.

6 Different clostridium species [21] and facultative anaerobic species [24] have been used

7 employing CSTR, batch, and UASB reactors [3]. COD reductions of around 80-90\%

8 and lactose consumption between 87 and 97\% have been reported [17-19, 21, 24, 25].

9 However, the residual liquid feed is still unsuitable for disposal as it contains different

10 organics such as acetic, propionic and butyric acids and ethanol together with unreacted

11 lactose.

13 The presence of these compounds in the residual stream has led other authors $[17,18]$ to

14 consider this residual effluent from $\mathrm{H}_{2}$ production for $\mathrm{CH}_{4}$ generation in anaerobic 15 continuous bioreactors. A COD removal of $95.3 \%$ has been achieved, with $2.2 \mathrm{~kg} / \mathrm{m}^{3}$ of

16 COD remaining after the two anaerobic processes. Azbar and Dokgoz [19] treated this

17 effluent by photo-fermentation with Rhodopseudomonas palustris in a two-step

18 biological process. The authors concluded the process was inadequate due to the

19 presence of nitrogen and volatile fatty acids in the solution. Diluting this effluent with

20 L-malic acid, which simultaneously improves hydrogen production, can partially solve

21 this problem and a final yield of 2-10 $\mathrm{mol} \mathrm{H}_{2} / \mathrm{mol}$ lactose has been reported. However,

22 the energy supplementation and the need for large volume bioreactors makes the 23 process unreliable [3]. 
1 Another interesting option for the treatment and valorisation of cheese whey effluents

2 that has not been considered before is the use of thermochemical processes. Among

3 these, catalytic steam reforming represents a challenging and promising alternative for

4 the treatment of these residues. Steam reforming is one of the most widespread

5 processes for the generation of a hydrogen-rich synthesis gas from organic compounds.

6 This catalytic process, which is carried out at atmospheric pressure and at moderate

7 temperatures, enables the organic matter of cheese whey to be transformed into a gas

8 with a high hydrogen content, up to 70 vol.\%, with many different posterior

9 applications [26]. It also reduces the organic matter of the original feedstock to

10 appropriate levels for safe discharge into the environment. A reaction pathway for

11 lactose steam reforming is provided in section 2.4.

12

13 The catalyst plays an important role in catalytic steam reforming. Specifically, it must

14 enhance the reaction rate of the reforming process, which includes both the reforming 15 reaction and the subsequent water gas shift (WGS) reaction. In addition, it must have

16 high deactivation resistance and sufficient strength if the process is to take place in a

17 fluidised bed reactor [27, 28]. A good approach to this challenge is using Ni-based

18 catalysts. A Ni-Co/Al-Mg catalyst, which has been proved to be suitable for the

19 catalytic steam reforming of bio-oil aqueous fractions [29, 30], was selected for this

20 work. This catalyst includes $\mathrm{Ni}$ as the active phase. Ni based catalysts meet the

21 challenge of being active and selective towards $\mathrm{H}_{2}$, although they are susceptible to

22 deactivation by coking. Therefore, the catalyst was modified with $\mathrm{Mg}$ and $\mathrm{Co} . \mathrm{Mg}$ was

23 added as a support modifier, enhancing the water adsorption in order to gasify the coke

24 or its precursors, as well as to provide more attrition resistance if the catalyst is to be

25 used in a fluidised bed. Co was added as an active phase modifier to enhance the steam 
1 reforming and WGS reactions and prevent catalyst deactivation by coking, as a Ni-Co

2 interaction can be formed in the catalyst which reduces the crystallite size [30].

4 Having a theoretical hydrogen yield of $24 \mathrm{~mol} \mathrm{H}_{2} / \mathrm{mol}$ lactose, this process could be 5 postulated as a suitable alternative for the treatment and valorisation of cheese whey. To 6 the best of the authors' knowledge, there are no studies in the literature concerning the 7 catalytic steam reforming of cheese whey or lactose solutions. Furthermore, the works 8 dealing with the catalytic steam reforming of sugars are extremely scarce. $\mathrm{Hu}$ and $\mathrm{Lu}$ 9 [31] studied the catalytic steam reforming of glucose for $\mathrm{H}_{2}$ production, analysing the effect of the reaction time $(0-3 \mathrm{~h})$, temperature $\left(300-600^{\circ} \mathrm{C}\right)$ and steam to carbon $(\mathrm{S} / \mathrm{C})$

11 ratio (3-9 mol $\mathrm{H}_{2} \mathrm{O} / \mathrm{mol} \mathrm{C}$ ) on the process. Marquevich et al. [32] reported the effect of 12 the temperature and $\mathrm{S} / \mathrm{C}$ ratio on the catalytic steam reforming of xylose, glucose and 13 sucrose. Both studies reached the same conclusions. An increase in the temperature 14 increases gas production and the yield to $\mathrm{H}_{2}$ and reduces char formation. The $\mathrm{S} / \mathrm{C}$ ratio 15 plays a very important role in the process, decreasing solid formation and enhancing gas 16 production, therefore high $\mathrm{S} / \mathrm{C}$ ratios are necessary to ensure a high carbon conversion 17 to gas. These sugars are unstable at high temperatures and decompose before reaching 18 the catalytic bed, which results in a serious formation of char in the upper part of the 19 reactor, thus decreasing the efficiency of the process. Therefore, it was claimed in both 20 works that minimising the thermal decomposition and avoiding char formation is one of 21 the main challenges during the steam reforming of sugars.

23 Given this background, this work analyses the catalytic steam reforming of a lactose 24 solution, both theoretically and experimentally, as a possible option for the treatment 
1 and valorisation of cheese whey effluents and/or lactose solutions. The theoretical study

2 addresses the effect of the temperature $\left(300-600{ }^{\circ} \mathrm{C}\right)$, lactose concentration $(1-10 \mathrm{wt} . \%)$,

3 and $\mathrm{N}_{2}\left(0-80 \mathrm{~cm}^{3} \mathrm{STP} / \mathrm{min}\right)$ and liquid flow $(0.1-0.5 \mathrm{~mL} / \mathrm{min})$ rates on the

4 thermodynamics of the process. The experimental part includes an in depth study of the

5 effect of the temperature $\left(300-600{ }^{\circ} \mathrm{C}\right)$, lactose concentration (1-10 wt.\%) and mass of

6 catalyst/lactose mass flow ratio (4-16 g catalyst $\mathrm{min} / \mathrm{g}$ lactose) in a fixed bed reactor

7 using a Ni-based catalyst.

9 For cheese whey valorisation, it is not only important to produce a hydrogen rich gas

10 from this waste, but also to come up with a carbon-free liquid stream that could be

11 discharged to the environment. Therefore, the effect of the operating variables on gas,

12 liquid and solid production and on the compositions of the gas and liquid phases has

13 been exhaustively analysed. Furthermore, optimal values for the operating variables

14 were sought and an energy balance was performed to provide a thorough technical and

15 energetic analysis of the process. Given that the catalytic steam reforming of cheese

16 whey or lactose solutions has never been reported before and that works dealing with

17 the steam reforming of sugars are very scarce, this work represents a challenging and

18 novel investigation not only for the management and valorisation of cheese whey but

19 also for hydrogen production from sugars or sugar-based streams by catalytic steam

20 reforming. 


\section{2. Experimental}

2

3 Different simulations based on a 2 level 4 factor Box-Wilson Central Composite Face

4 Centred $(\mathrm{CCF}, \alpha: \pm 1)$ design were carried out to analyse the influence on the

5 thermodynamic gas composition (vol.\%) of the reforming temperature $\left(300-600{ }^{\circ} \mathrm{C}\right)$,

6 lactose concentration (1-10 wt. \%), flow rate of $\mathrm{N}_{2}\left(0-80 \mathrm{~cm}^{3} \mathrm{STP} / \mathrm{min}\right)$ and liquid flow

7 rate (0.1-0.5 $\mathrm{mL} / \mathrm{min})$. The gas composition (vol.\%) was theoretically calculated with

8 the aid of the software Hysys 8.4 using the Gibbs energy minimisation method. Four

9 thermodynamic packages (PRSV, Twu-Sim-Tasonee, Lee-Kesler-Plöcker and BWRS)

10 were used for the calculations. This Gibbs reactor utility provides the theoretical

11 equilibrium composition minimising the Gibbs free energy of the system, which allows

12 calculating the thermodynamic equilibrium without introducing the reaction

13 stoichiometry, as described in the works of Chen et al. [33], Wang et al. [34] and Duo et

14 al. [35] For this calculation, $\mathrm{H}_{2}, \mathrm{CO}, \mathrm{CO}_{2}, \mathrm{CH}_{4}, \mathrm{C}_{2} \mathrm{H}_{2}, \mathrm{C}_{2} \mathrm{H}_{4}, \mathrm{C}_{2} \mathrm{H}_{6}$ were considered as

15 output products for lactose steam reforming, which is in good agreement with the output

16 products normally selected in reforming processes [34]. The results were analysed by

17 means of an ANOVA test with 95\% confidence. Furthermore, the relative influence of

18 the operating variables was calculated using the cause-effect Pareto principle.

\subsection{Experimental reforming study}

21 The experimental study addresses the influence of the reforming temperature (300-600

$\left.22{ }^{\circ} \mathrm{C}\right)$, lactose concentration (1-10 wt.\%) and ratio mass of the catalyst/lactose mass flow

23 rate $\left(\mathrm{W} / \mathrm{m}_{\text {lactose }}=4-16 \mathrm{~g}\right.$ catalyst $\mathrm{min} / \mathrm{g}$ lactose $)$ on the catalytic steam reforming of

24 lactose. The experiments were planned using a 2 level 3 factor Box-Wilson Central 
1 Composite Face Centred (CCF, $\alpha: \pm 1)$ design. The results were analysed with an

2 analysis of variance (ANOVA) with 95\% confidence and the cause-effect Pareto

3 principle was used to determine their relative influence on the process. This

4 corresponds to a $2^{\mathrm{k}}$ factorial design, where $\mathrm{k}$ indicates the number of factors studied (in

5 this case 3 operating variables) and $2^{\mathrm{k}}$ represents the number of runs (in this case 8 ) for

6 the simple factorial design. 10 axial experiments were performed to study non-linear

7 effects and interactions according to the CCF design. In addition, four replicates at the

8 centre point (centre of the variation interval of each factor) were carried out in order to

9 evaluate the experimental error. This experimental design is suitable not only for

10 studying the influence of each variable (linear and quadratic effects) but also for

11 understanding possible interactions between variables.

13 The experimental rig used in the experiments was a microactivity unit designed and

14 built by PID (Process Integral Development Eng \& Tech, Spain). It consists of a small

15 bench scale rig comprising a fixed bed reactor of $25 \mathrm{~mm}$ in height and $9 \mathrm{~mm}$ inner

16 diameter. The lactose solutions were fed into the reactor with a HPLC pump. $\mathrm{N}_{2}$ was

17 used as a carrier gas to facilitate the feeding of the solutions, as well as an internal

18 standard for gas quantification. Liquid and $\mathrm{N}_{2}$ flow rates of $0.4 \mathrm{~mL} / \mathrm{min}$ and 40

$19 \mathrm{~cm}^{3} \mathrm{STP} / \mathrm{min}$ were used, respectively. Once inside the reactor, the feed down-flow

20 passed through the catalytic bed, consisting of a mixture of catalyst and inert sand. The

21 gaseous mixture passed to a condensation system consisting of a stainless steel vessel

22 cooled by means of a Peltier thermoelectric cell where the condensable vapours were

23 trapped. The permanent gases exiting the condensation system were analysed online

24 with a micro gas chromatograph equipped with thermal conductivity detectors. More

25 details concerning the set-up can be found in our previous communications $[29,30,36]$. 
2 A Ni-Co/Al-Mg catalyst prepared by coprecipitation was selected. The preparation

3 involved adding a solution of $\mathrm{NH}_{4} \mathrm{OH}$ to a solution containing $\mathrm{Ni}\left(\mathrm{NO}_{3}\right)_{2} \cdot 6 \mathrm{H}_{2} \mathrm{O}$,

$4 \mathrm{Al}\left(\mathrm{NO}_{3}\right)_{3} \cdot 9 \mathrm{H}_{2} \mathrm{O}, \mathrm{Mg}\left(\mathrm{NO}_{3}\right)_{2} \cdot 6 \mathrm{H}_{2} \mathrm{O}$ and $\mathrm{Co}\left(\mathrm{NO}_{3}\right)_{2} \cdot 6 \mathrm{H}_{2} \mathrm{O}$ dissolved in milli-Q water until a

$5 \mathrm{pH}$ of 8.2 was reached, in a similar manner as reported in the work of Wang et al. [34].

6 The precipitation medium was maintained at $40{ }^{\circ} \mathrm{C}$ and moderately stirred. The

7 hydrated precursor was filtered, washed at $40{ }^{\circ} \mathrm{C}$ and dried overnight at $105^{\circ} \mathrm{C}$.

8 Afterwards it was ground and sieved to a particle size ranging from 160 to $320 \mu \mathrm{m}$ and

9 calcined in an air atmosphere up to a temperature of $750{ }^{\circ} \mathrm{C}$ for $3 \mathrm{~h}$. Finally, it was

10 activated in situ prior to reaction with $\mathrm{H}_{2}$ at $650^{\circ} \mathrm{C}$.

12 The catalyst has a $28 \%$ (relative atomic percentage) Ni expressed as

$13 \mathrm{Ni} /(\mathrm{Ni}+\mathrm{Co}+\mathrm{Al}+\mathrm{Mg})$, an atomic $\mathrm{Mg} / \mathrm{Al}$ ratio of 0.26 and an atomic $\mathrm{Co} / \mathrm{Ni}$ ratio of 0.10 ,

14 with a BET surface area of about $132 \mathrm{~m}^{2} / \mathrm{g}$. Crystalline phases of $\mathrm{NiO} / \mathrm{MgO}$ and

$15 \mathrm{NiAl}_{2} \mathrm{O}_{4} / \mathrm{MgAl}_{2} \mathrm{O}_{4}$ spinels were found in the X-ray diffraction (XRD) analysis of the

16 calcined precursor. No crystalline phases of Co were detected by XRD. These

17 crystalline phases are consistent with the TPR analyses, where two peaks were detected.

18 A small peak was found at $300-320{ }^{\circ} \mathrm{C}$, corresponding to the reduction of the $\mathrm{NiO}$ phase

19 as well as the reduction of the $\mathrm{Co}_{3} \mathrm{O}_{4}$ phase [37-39]. This may suggest a high Ni-Co

20 interaction, which was confirmed by the positive shift of the binding energy of Ni $2 p_{3 / 2}$

21 detected in the XPS analysis. A second higher intensity peak was found at $732{ }^{\circ} \mathrm{C}$,

22 which might correspond to the reduction of the $\mathrm{NiAl}_{2} \mathrm{O}_{4}$ spinel phase. Further

23 information about the characterisation of the catalyst can be found in our previous

24 communication [30]. 
1 The lactose solutions were prepared dissolving D-lactose monohydrate $\left(\mathrm{C}_{12} \mathrm{H}_{22} \mathrm{O}_{11} \cdot \mathrm{H}_{2} \mathrm{O}\right.$

2 Sigma Aldrich, CAS Number 64044-51-5, Bio-Ultra >99.5\% HPLC) in Milli-Q water. 3

$4 \quad$ Table 1. Response variables. Definitions and analytical techniques used in their 5 determination.

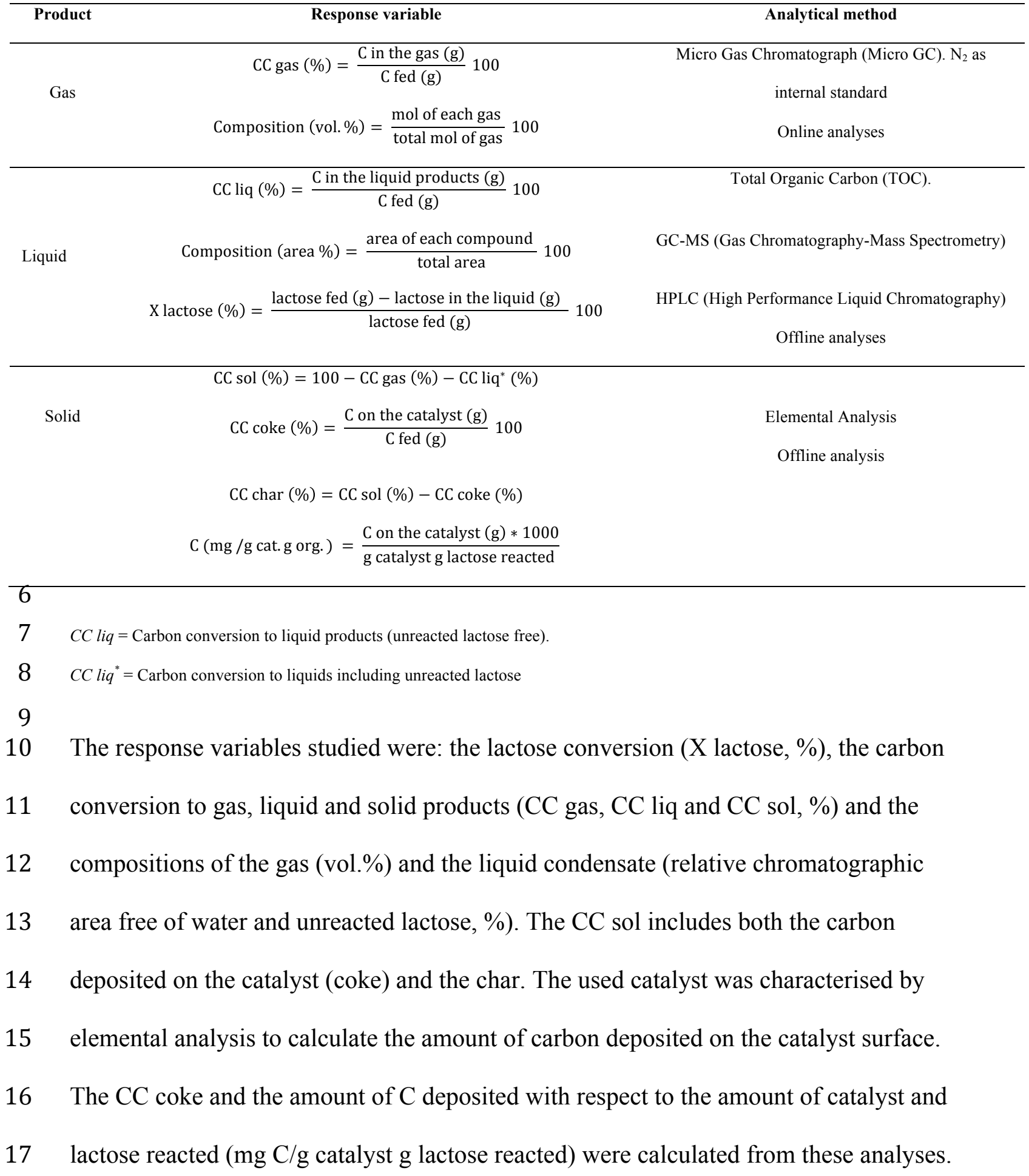


1 Table 1 summarises the response variables and the analytical methods used for their

2 calculation.

3

\section{$4 \quad 2.3$ Data analysis}

5 In the simulations made for the theoretical study and in the fixed bed experiments, the

6 lower and upper limits of all the factors (temperature, lactose concentration and liquid

7 and $\mathrm{N}_{2}$ flow rates in the theoretical study and temperature, lactose concentration and

$8 \mathrm{~W} / \mathrm{m}_{\text {lactose }}$ ratio in the experimental study) were normalised from -1 to 1 (codec factors).

9 This codification permits all factors to vary within the same interval and helps to

10 investigate their influence in comparable terms.

12 The experimental study analyses the effect of the operating conditions on the response

13 variables as well as the evolution of the response variables with time. To analyse the

14 evolution with time, the results are presented divided into three intervals of 60 minutes.

15 Each interval provides the average value of the response variable obtained during 60

16 minutes of experiment. All these values (three per experiment) have been compared

17 using a one-way analysis of variance (one-way ANOVA) and Fisher's least significant

18 difference (LSD) test, both with $95 \%$ confidence. The results of the ANOVA analyses

19 are provided as p-values. P-values lower than 0.05 indicate that at least two values are

20 significantly different. The LSD test was used to compare pairs of data, i.e. either

21 between two intervals of the same experiment or between two intervals of two different

22 experiments. The results of the LSD tests are presented graphically in the form of LSD

23 bars. To ensure significant differences between any pairs of data, their LSD bars must

24 not overlap. 
2 The effect of the operating variables on the process has been studied considering the

3 results corresponding to the first 60 minutes of reaction using a statistical analysis of

4 variance (one-way ANOVA) test with 95\% confidence. This avoids including the

5 activity variation with time in the analysis. The ANOVA analysis helped to select the

6 operating variables and interactions that significantly influence the response variables

7 under consideration. In addition, the cause-effect Pareto principle was also used to

8 calculate their relative importance on the process.

2.4 Possible reaction network for lactose steam reforming

11 Lactose steam reforming includes reforming, cracking and thermal decomposition

12 reactions due to the instability of sugars at high temperatures [31, 32].

$14 \quad 1$ - Reforming reactions:

15 Steam reforming of the oxygenated compounds: lactose and intermediate products

$$
\mathrm{C}_{12} \mathrm{H}_{22} \mathrm{O}_{11}+\mathrm{H}_{2} \mathrm{O} \rightarrow 12 \mathrm{CO}+12 \mathrm{H}_{2}\left(\Delta \mathrm{H}_{298 \mathrm{~K}}=1181 \mathrm{~kJ} / \mathrm{mol}\right)
$$

$$
\mathrm{C}_{\mathrm{n}} \mathrm{H}_{\mathrm{m}} \mathrm{O}_{\mathrm{k}}+(\mathrm{n}-\mathrm{k}) \mathrm{H}_{2} \mathrm{O} \Leftrightarrow \mathrm{n} \mathrm{CO}+(\mathrm{n}+\mathrm{m} / 2-\mathrm{k}) \mathrm{H}_{2}
$$

Water gas shift (WGS) reaction:

$$
\mathrm{CO}+\mathrm{H}_{2} \mathrm{O} \Leftrightarrow \mathrm{CO}_{2}+\mathrm{H}_{2} \quad\left(\Delta \mathrm{H}_{298 \mathrm{~K}}=-41 \mathrm{~kJ} / \mathrm{mol}\right)
$$

Methane steam reforming and dry reforming:

$$
\mathrm{CH}_{4}+\mathrm{H}_{2} \mathrm{O} \Leftrightarrow \mathrm{CO}+3 \mathrm{H}_{2} \quad\left(\Delta \mathrm{H}_{298 \mathrm{~K}}=206 \mathrm{~kJ} / \mathrm{mol}\right)
$$

$$
\mathrm{CH}_{4}+2 \mathrm{H}_{2} \mathrm{O} \Leftrightarrow \mathrm{CO}_{2}+4 \mathrm{H}_{2}\left(\Delta \mathrm{H}_{298 \mathrm{~K}}=165 \mathrm{~kJ} / \mathrm{mol}\right)
$$

$$
\mathrm{CH}_{4}+\mathrm{CO}_{2} \Leftrightarrow 2 \mathrm{CO}+2 \mathrm{H}_{2} \quad\left(\Delta \mathrm{H}_{298 \mathrm{~K}}=247 \mathrm{~kJ} / \mathrm{mol}\right)
$$


$1 \quad \underline{2-\text { Thermal decomposition and cracking reactions }}$

$2 \quad \mathrm{C}_{\mathrm{n}} \mathrm{H}_{\mathrm{m}} \mathrm{O}_{\mathrm{k}} \rightarrow$ Liquids $\left(\mathrm{C}_{\mathrm{x}} \mathrm{H}_{\mathrm{y}} \mathrm{O}_{\mathrm{z}}\right)+\mathrm{Gas}\left(\mathrm{H}_{2}, \mathrm{CO}, \mathrm{CO}_{2}, \mathrm{CH}_{4}, \ldots\right)+$ carbon

3

4

7 The thermal decomposition of lactose produces organic liquid intermediates of different

8 nature, gases and carbonaceous residues. Figure 1 shows a possible reaction pathway

9 for the formation of the most important liquid products during the thermal

10 decomposition of lactose, taking into account the work of Carlson et al. [40]. The

11 formation of these compounds starts with an initial lactose decomposition by hydrolysis

12 into glucose and galactose, which can be subsequently decomposed into other

13 intermediate liquids. At a low temperature and low pyrolysis rate, both monomers

14 evolve towards the formation of oxygenated compounds of low molecular mass such as

15 acids, aldehydes, ketones and alcohols by retro-aldol and grob fragmentation reactions. 
1 At high temperatures and a fast pyrolysis rate the formation of anhydrosugars is

2 favoured. These compounds can subsequently be dehydrated to give furanic

3 compounds. Mono-aromatic compounds can be formed from both furans and small-

4 oxygenates by oligomerisation, decarboxylation and decarbonylation reactions. Poly-

5 aromatic species can be produced as a final step from mono-aromatics.

\section{3. Results and discussion}

\section{$8 \quad 3.1$ Theoretical study}

9 Table 2 shows the simulations performed and the results obtained in the theoretical

10 study. For each gas an empirical model that relates the operating variables (temperature,

11 lactose concentration, $\mathrm{N}_{2}$ and liquid flow rates) to the volumetric composition of the gas

12 was developed according to the ANOVA analysis. The relative influence of each factor

13 in the model was calculated making use of the cause-effect Pareto principle. The results

14 of these analyses are summarised in Table 3.

16 The thermodynamic results predict a complete lactose conversion to gas for all the

17 simulations. Lactose has a $\mathrm{C} / \mathrm{O}$ ratio close to 1 , which permits complete conversion to

18 be achieved at low temperatures $[31,41]$. The ANOVA analysis reveals that the

19 temperature, lactose concentration, liquid flow rate and $\mathrm{N}_{2}$ flow rate have a statistically

20 significant influence on the equilibrium composition of the gas ( $p$-values $<0.05)$,

21 although their relative influence is different. The cause-effect Pareto analysis shows that

22 the gas composition is strongly affected (more than 77 of relative influence) by the

23 temperature, concentration of lactose and an interaction between these two variables. 
1 The weak influence of the liquid and $\mathrm{N}_{2}$ flow rates is related to the small variations in

2 the partial pressures inside the reactor when varying these flow rates, which have a

3 slight affect on the thermodynamic equilibrium [33]. As a direct consequence, the

4 majority of works dealing with steam reforming only consider the effects of the

5 concentration of the organic compounds (or steam to carbon ratio, S/C) and the

6 temperature in thermodynamic studies.

7

8 Table 2. Thermodynamic gas composition results for the simulations. The gas

9 composition is expressed as the 95\% confidence interval for the mean obtained with the

10 different thermodynamic packages.

11

\begin{tabular}{|c|c|c|c|c|c|c|c|c|c|c|c|c|}
\hline \multirow[t]{2}{*}{ Sim } & \multicolumn{2}{|c|}{$\begin{array}{c}\text { [Lactose] } \\
\text { (wt.\%) }\end{array}$} & \multicolumn{2}{|c|}{$\begin{array}{c}Q_{\text {liq }} \\
\text { (mL/min) } \\
\end{array}$} & \multicolumn{2}{|c|}{$\begin{array}{c}\mathbf{Q}_{\mathrm{N} 2} \\
(\mathrm{~mL} / \mathrm{min}) \\
\end{array}$} & \multicolumn{2}{|c|}{$\begin{array}{c}\mathrm{T} \\
\left({ }^{\circ} \mathrm{C}\right)\end{array}$} & \multirow[t]{2}{*}{$\begin{array}{c}\mathrm{H}_{2} \\
(\mathrm{vol} \% \text { \%) } \\
\end{array}$} & \multirow[t]{2}{*}{$\begin{array}{c}\mathrm{CO}_{2} \\
(\mathrm{vol} \% \%) \\
\end{array}$} & \multirow[t]{2}{*}{$\begin{array}{c}\text { CO } \\
(\text { vol. } \%) \\
\end{array}$} & \multirow[t]{2}{*}{$\begin{array}{c}\mathrm{CH}_{4} \\
(\mathrm{vol} \% \%) \\
\end{array}$} \\
\hline & Codec & Actual & Codec & Actual & Codec & Actual & Codec & Actual & & & & \\
\hline 1 & -1 & 1 & -1 & 0.1 & -1 & 0 & -1 & 300 & $66.60-66.62$ & $33.20-33.22$ & $0.001-0.001$ & $0.173-0.176$ \\
\hline 2 & 1 & 10 & -1 & 0.1 & -1 & 0 & -1 & 300 & $37.21-37.27$ & $40.55-40.57$ & $0.039-0.039$ & $22.14-22.18$ \\
\hline 3 & -1 & 1 & 1 & 0.5 & -1 & 0 & -1 & 300 & $66.60-66.62$ & $33.20-33.22$ & 0.009-0.009 & $0.173-0.176$ \\
\hline 4 & 1 & 10 & 1 & 0.5 & -1 & 0 & -1 & 300 & $37.21-37.27$ & $40.55-40.56$ & $0.039-0.039$ & $22.14-22.18$ \\
\hline 5 & -1 & 1 & -1 & 0.1 & 1 & 80 & -1 & 300 & $66.76-66.76$ & $33.17-33.17$ & 0.009-0.009 & $0.065-0.066$ \\
\hline 6 & 1 & 10 & -1 & 0.1 & 1 & 80 & -1 & 300 & $42.38-42.39$ & $39.25-39.26$ & $0.048-0.048$ & $18.30-18.31$ \\
\hline 7 & -1 & 1 & 1 & 0.5 & 1 & 80 & -1 & 300 & $66.66-66.66$ & $33.20-33.20$ & 0.009-0.009 & $0.137-0.138$ \\
\hline 8 & 1 & 10 & 1 & 0.5 & 1 & 80 & -1 & 300 & $38.48-38.52$ & $40.24-40.26$ & $0.041-0.041$ & $21.19-21.21$ \\
\hline 9 & -1 & 1 & -1 & 0.1 & -1 & 0 & 1 & 600 & $66.77-66.78$ & $33.07-33.07$ & $0.154-0.155$ & $0.00-0.00$ \\
\hline 10 & 1 & 10 & -1 & 0.1 & -1 & 0 & 1 & 600 & $66.25-66.26$ & $32.02-32.02$ & $1.720-1.721$ & $0.007-0.007$ \\
\hline 11 & -1 & 1 & 1 & 0.5 & -1 & 0 & 1 & 600 & $66.77-66.78$ & $33.07-33.07$ & $0.154-0.155$ & $0.00-0.00$ \\
\hline 12 & 1 & 10 & 1 & 0.5 & -1 & 0 & 1 & 600 & $66.25-66.26$ & $32.02-32.02$ & $1.720-1.721$ & $0.007-0.007$ \\
\hline 13 & -1 & 1 & -1 & 0.1 & 1 & 80 & 1 & 600 & $66.78-66.78$ & $33.07-33.07$ & $0.154-0.154$ & $0.00-0.00$ \\
\hline 14 & 1 & 10 & -1 & 0.1 & 1 & 80 & 1 & 600 & $66.26-66.26$ & $32.02-32.02$ & $1.720-1.721$ & $0.003-0.003$ \\
\hline 15 & -1 & 1 & 1 & 0.5 & 1 & 80 & 1 & 600 & $66.78-66.78$ & $33.07-33.07$ & $0.154-0.155$ & 0.00-0.00 \\
\hline 16 & 1 & 10 & 1 & 0.5 & 1 & 80 & 1 & 600 & $66.26-66.26$ & $32.09-32.09$ & $1.720-1.721$ & $0.005-0.005$ \\
\hline 17 & 0 & 5.5 & 0 & 0.3 & 0 & 40 & 0 & 450 & $66.62-66.62$ & $32.99-32.99$ & $0.310-0.311$ & $0.078-0.078$ \\
\hline 18 & -1 & 1 & 0 & 0.3 & 0 & 40 & 0 & 450 & $66.82-66.82$ & $33.13-33.13$ & $0.053-0.053$ & $0.00-0.00$ \\
\hline 19 & 1 & 10 & 0 & 0.3 & 0 & 40 & 0 & 450 & $65.54-65.54$ & $33.05-33.05$ & $0.585-0.585$ & $0.819-0.819$ \\
\hline 20 & 0 & 5.5 & -1 & 0.1 & 0 & 40 & 0 & 450 & $66.65-66.65$ & $32.98-32.98$ & $0.311-0.311$ & $0.055-0.055$ \\
\hline 21 & 0 & 5.5 & 1 & 0.5 & 0 & 40 & 0 & 450 & $66.62-66.62$ & $32.99-32.99$ & $0.310-0.310$ & $0.084-0.084$ \\
\hline 22 & 0 & 5.5 & 0 & 0.3 & -1 & 0 & 0 & 450 & $66.61-66.61$ & $32.98-32.98$ & 0.309-0.309 & $0.095-0.095$ \\
\hline 23 & 0 & 5.5 & 0 & 0.3 & 1 & 80 & 0 & 450 & $66.65-66.65$ & $32.98-32.98$ & $0.311-0.311$ & $0.065-0.065$ \\
\hline 24 & 0 & 5.5 & 0 & 0.3 & 0 & 40 & -1 & 300 & $50.82-50.82$ & $37.16-37.16$ & $0.033-0.033$ & $11.98-11.98$ \\
\hline 25 & 0 & 5.5 & 0 & 0.3 & 0 & 40 & 1 & 600 & $66.54-66.54$ & $32.57-32.57$ & $0.895-0.895$ & 0.001-0.001 \\
\hline
\end{tabular}

12

13

14 Taking this information into account, two different models were developed. The first

15 was a full model used for prediction purposes which includes all the significant effects

16 and interactions of the four operating variables. The second was a simplified model

17 which only includes the effects of the temperature, the lactose concentration and

18 temperature-lactose concentration interactions. This was used for studying the

19 thermodynamics of the process. The full model (not shown) indicates that the relative 
1 amounts of $\mathrm{H}_{2}, \mathrm{CO}_{2}, \mathrm{CO}$ and $\mathrm{CH}_{4}$ in the gas vary as follows: $38.2-69.0$ vol.\%, 31.7-40.3

2 vol. $\%, 0.0-1.7$ vol. $\%$ and $0.0-21.0$ vol. $\%$, respectively.

$4 \quad$ Table 3. Relative influence of the studied variables and their interactions on the

5 thermodynamic composition of the gas according to the ANOVA analysis for the

6 simplified model

7

\begin{tabular}{|c|c|c|c|c|c|c|c|}
\hline & Independent term & $\mathbf{T}$ & $\mathbf{C}$ & T C & $\mathbf{T}^{2}$ & $\mathbf{T}^{2} \mathbf{C}$ & Others \\
\hline $\mathrm{H}_{2}($ vol.\%) & 66.59 & $\begin{array}{l}6.91 \\
(26)\end{array}$ & ns & $\begin{array}{l}6.82 \\
(25)\end{array}$ & $\begin{array}{c}-7.22 \\
(10)\end{array}$ & $\begin{array}{c}-7.08 \\
(26)\end{array}$ & (13) \\
\hline $\mathrm{CO}_{2}($ vol. $\%)$ & 32.99 & $\begin{array}{c}-2.07 \\
(30)\end{array}$ & ns & $\begin{array}{c}-2 \\
(28)\end{array}$ & $\begin{array}{c}1.69 \\
(9)\end{array}$ & $\begin{array}{l}1.48 \\
(21)\end{array}$ & (13) \\
\hline CO (vol.\%) & 0.31 & $\begin{array}{l}0.46 \\
(35)\end{array}$ & $\begin{array}{l}0.27 \\
(30)\end{array}$ & $\begin{array}{l}0.38 \\
(29)\end{array}$ & $\begin{array}{c}0.17 \\
(5)\end{array}$ & $\begin{array}{c}0.13 \\
(2)\end{array}$ & (1) \\
\hline $\mathrm{CH}_{4}(\mathrm{vol} . \%)$ & 0.11 & $\begin{array}{c}-5.29 \\
(26)\end{array}$ & ns & $\begin{array}{l}-5.2 \\
(25)\end{array}$ & $\begin{array}{l}5.37 \\
(10)\end{array}$ & $\begin{array}{l}5.21 \\
(25)\end{array}$ & (13) \\
\hline
\end{tabular}

8

19

ns. Non significant with $95 \%$ confidence

Response variable $=$ Independent term + Coefficient $\mathrm{T} \cdot \mathrm{T}+$ Coefficient $\mathrm{C} \cdot \mathrm{C}+$ Coefficient $\mathrm{TC} \cdot \mathrm{TC}+$ Coefficient $\mathrm{T}^{2} \cdot \mathrm{T}^{2}+$ Coefficient $\mathrm{T}^{2} \mathrm{C} \cdot \mathrm{T}^{2} \mathrm{C}$

13 Table 3 shows the terms of the simplified model and the relative importance of all the

14 variables according to the Pareto test. The effects of the $\mathrm{N}_{2}$ and liquid flow rates and

15 their interactions have been grouped together under the term "others". The lack of fit for

16 all the simplified models is not significant in comparison with the pure error ( $\mathrm{p}$-value $>$

170.05 ) and their $\mathrm{R}^{2}$ is higher than 0.99 in all cases. In addition, no significant differences

18 were observed between the values predicted with the models and the values obtained in

19 the simulations, with $95 \%$ confidence. This indicates that they are able to predict up to

$2099 \%$ of the variations observed, confirming the slight effect of the liquid and $\mathrm{N}_{2}$ flow

21 rates on the thermodynamic results in this work and the good accuracy of the models

22 developed.

24 As regards the relative influence of the operating variables on the process, the codec

25 model listed in Table 3 shows that within the interval of study considered in this work,

26 the temperature (the linear term and its interaction with the lactose concentration) exerts 
1 the highest influence on the equilibrium composition. The quadratic effect for the

2 temperature $\left(\mathrm{T}^{2}\right)$ is significant, which indicates the existence of maxima and minima.

3 Conversely, quadratic terms for the lactose concentration are not significant with $95 \%$

4 confidence, denoting a linear evolution for this operating variable. In addition, a

5 significant interaction between the temperature and the concentration of lactose was

6 detected; therefore the effect of the lactose concentration depends on the temperature

7 and vice versa. The effect of the temperature is related to the variations of the

8 thermodynamic equilibrium constant of all the reactions involved in the process, while

9 the effect of the concentration (1-10 wt.\%) is linked to the variations in the water

10 content of the solutions (variations in the $\mathrm{S} / \mathrm{C}$ ratio from 157 to $14 \mathrm{~mol} \mathrm{H}_{2} \mathrm{O} / \mathrm{mol} \mathrm{C}$ ).

11 High $\mathrm{S} / \mathrm{C}$ ratios help to shift the WGS and methane reforming reactions towards the

12 formation of $\mathrm{H}_{2}$ [42].

14 Figure 2 shows the interaction plots between the temperature and lactose concentration

15 obtained from the models shown in Table 3, obtained from the statistical analysis of the

16 results obtained in the simulations listed in Table 2. Specifically, the volumetric gas

17 composition (vol.\%) is plotted as a function of the temperature for the lowest and the

18 highest (1 and $10 \mathrm{wt. \% )}$ lactose concentrations employed in this work. In general, an

19 increase in the temperature between 300 and $600{ }^{\circ} \mathrm{C}$ increases the proportions of $\mathrm{H}_{2}$ and

$20 \mathrm{CO}$ in the gas, reducing the relative amounts of $\mathrm{CO}_{2}$ and $\mathrm{CH}_{4}$. The reforming reaction

21 of lactose (Eq. 1) is highly endothermic and the water gas shift reaction (Eq. 3) is

22 moderately exothermic [31], giving an overall endothermic process. Thus, an increase

23 in temperature augments the equilibrium concentration of $\mathrm{H}_{2}$ and $\mathrm{CO}$ in the gas. The

24 proportions of $\mathrm{CH}_{4}$ and $\mathrm{CO}_{2}$ in the gas decrease due to the endothermic nature of the 
1 reforming (Eqs. 4-5) and dry reforming (Eq.6) of methane as well as the exothermic

2 character of the WGS reaction, respectively [42].

a)

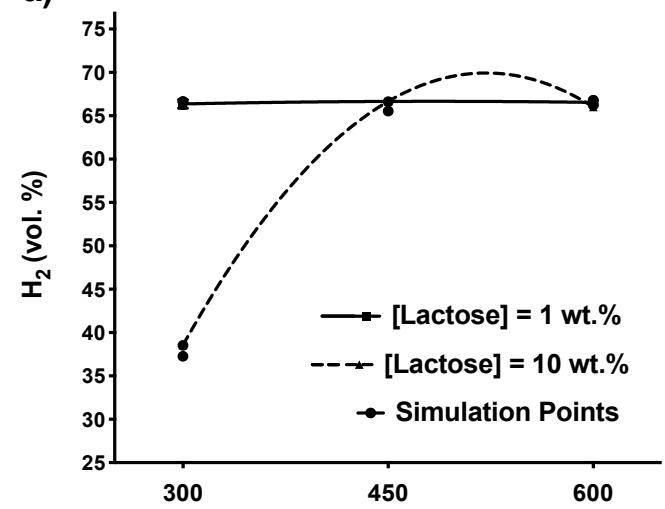

c)

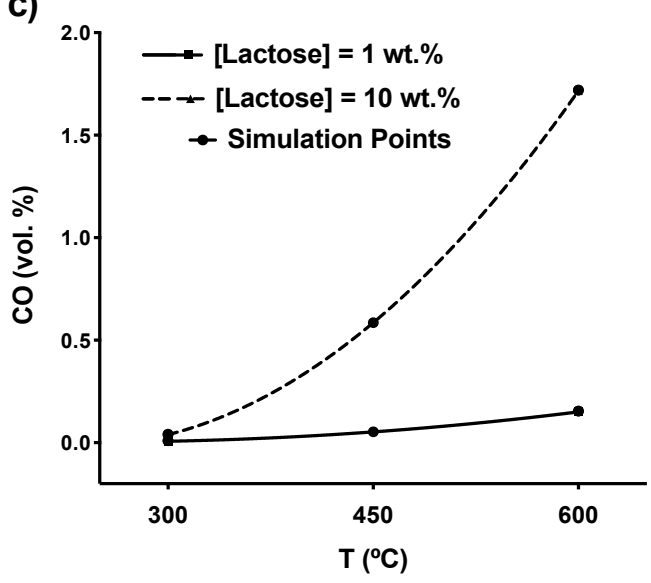

b)

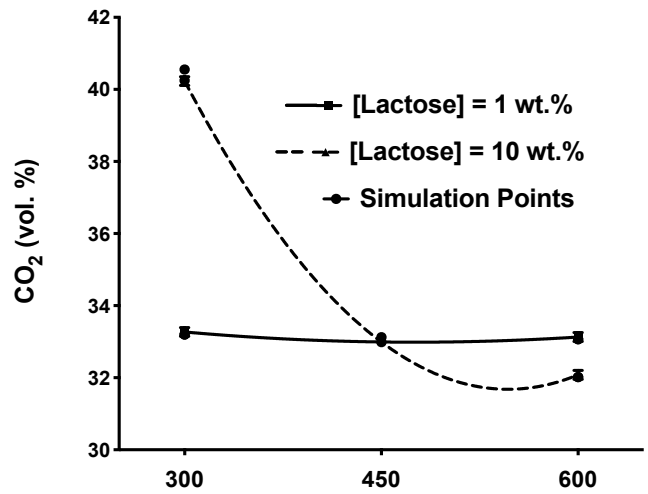

d)

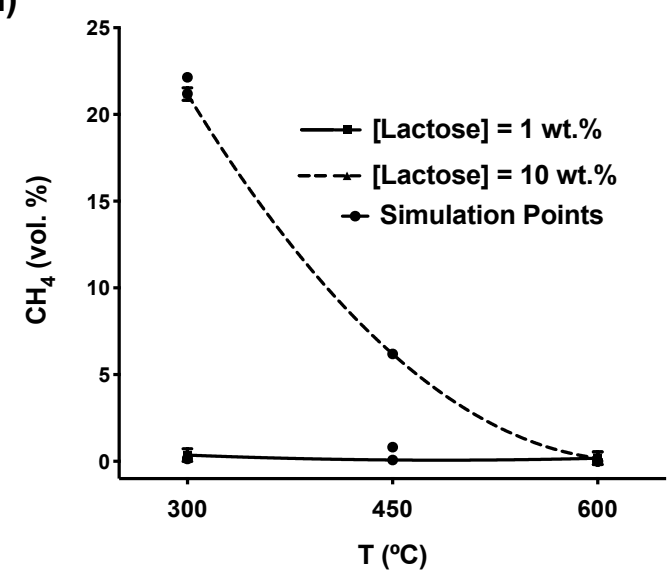

$4 \quad$ Figure 2. Evolution with temperature of the thermodynamic concentration of $\mathrm{H}_{2}(\mathrm{a})$,

$5 \mathrm{CO}_{2}(\mathrm{~b}), \mathrm{CO}(\mathrm{c})$ and $\mathrm{CH}_{4}(\mathrm{~d})$ for the lowest (1 wt.\%) and highest (10 wt.\%) lactose

6 concentrations obtained with an ANOVA analysis of the simulations.

8 These variations are more appreciable as the concentration of lactose in the solution

9 increases due to the significant interaction between the temperature and the lactose

10 concentration. This makes the effect of the temperature on the composition of the gas

11 extremely weak for very diluted lactose solutions (1 wt.\%) due to the large amount of

12 water employed $\left(\mathrm{S} / \mathrm{C}=157 \mathrm{~mol} \mathrm{H}_{2} \mathrm{O} / \mathrm{mol} \mathrm{C}\right)$. 
1 Conversely, an increase in the lactose concentration from 1 to $10 \mathrm{wt} . \%$ increases the

2 effect of the temperature. An increase in the lactose concentration has two different

3 consequences depending on the temperature. On the one hand, between 300 and $450{ }^{\circ} \mathrm{C}$,

4 an increase in the amount of lactose in the solution reduces the proportion of $\mathrm{H}_{2}$,

5 augmenting the relative amounts of $\mathrm{CO}_{2}$ and $\mathrm{CH}_{4}$ in the gas. Within this temperature

6 range, an increase in the concentration of lactose diminishes the excess of water, thus

7 decreasing the steam to carbon $(\mathrm{S} / \mathrm{C})$ ratio of the solution from 157 to $14 \mathrm{~mol} \mathrm{H}_{2} \mathrm{O} / \mathrm{mol}$

8 C. This originates a lesser shift of the WGS and methane reforming reactions towards

$9 \mathrm{H}_{2}$ production.

11 On the other hand, between 450 and $600{ }^{\circ} \mathrm{C}$, the same increment in the concentration of

12 lactose increases the proportions of $\mathrm{H}_{2}$ and $\mathrm{CO}$ and reduces the concentration of $\mathrm{CO}_{2}$ in

13 the gas. The variation in the relative amount of $\mathrm{H}_{2}$ is relatively small, since the optimum

14 for $\mathrm{H}_{2}$ production is found to be at temperatures around $500-550{ }^{\circ} \mathrm{C}$. These variations

15 are the consequence of the greater spread of reforming reactions at high temperature,

16 which favours $\mathrm{H}_{2}$ production.

18 3.2 Experimental study

19 3.2.1 Global lactose conversion and carbon distribution: CC gas, CC liq and CC sol.

20 Table 4 lists the experiments performed in the fixed bed reactor. A complete and steady

21 global lactose conversion (X lactose) was achieved in all the experiments, indicating

22 that all the lactose was converted into gas, liquid and solid products. The $\mathrm{C} / \mathrm{O}$ ratio close

23 to 1 of lactose allows complete conversion to be achieved even at the lowest 
1 temperature used in this work [31, 41]. Complete conversions were achieved at

2 temperatures higher than $500{ }^{\circ} \mathrm{C}$ in the work of $\mathrm{Hu}$ et al. [31] during the steam

3 reforming of glucose. Figure 3 shows the $\mathrm{CC}$ gas, $\mathrm{CC}$ liq and $\mathrm{CC}$ sol obtained for the

4 experiments in three intervals of $60 \mathrm{~min}$. The statistical analysis reveals significant

5 differences between the results obtained in the experiments for the CC gas, CC liq and

6 CC sol (p-values $<0.001$ ), which vary as follows: $2-97 \%, 0-66 \%$ and $0-95 \%$,

7 respectively. In addition, increases and reductions in the $\mathrm{CC}$ gas, $\mathrm{CC}$ liq and $\mathrm{CC}$ sol are

8 detected in some experiments.

10 Table 4. Experimental operating conditions (actual and codec values) used in the 11 experiments.

12

\begin{tabular}{|c|c|c|c|c|c|c|}
\hline \multirow[t]{2}{*}{ Run } & \multicolumn{2}{|c|}{$\begin{array}{c}\text { Temperature } \\
\left({ }^{\circ} \mathrm{C}\right)\end{array}$} & \multicolumn{2}{|c|}{$\begin{array}{l}\text { [Lactose] } \\
\text { (wt.\%) }\end{array}$} & \multicolumn{2}{|c|}{$\begin{array}{c}\mathrm{W} / \mathrm{m}_{\text {lactosa }} \\
(\text { g catalyst } \mathrm{min} / \mathrm{g} \text { lactose) }\end{array}$} \\
\hline & Codec & Actual & Codec & Actual & Codec & Actual \\
\hline 1 & -1 & 300 & -1 & 1 & -1 & 4 \\
\hline 2 & 1 & 600 & -1 & 1 & -1 & 4 \\
\hline 3 & -1 & 300 & -1 & 1 & 1 & 16 \\
\hline 4 & 1 & 600 & -1 & 1 & 1 & 16 \\
\hline 5 & -1 & 300 & 1 & 10 & 1 & 4 \\
\hline 6 & 1 & 600 & 1 & 10 & 1 & 4 \\
\hline 7 & -1 & 300 & 1 & 10 & 1 & 16 \\
\hline 8 & 1 & 600 & 1 & 10 & 1 & 16 \\
\hline $9 *(9,10,11,12)$ & 0 & 450 & 0 & 5.5 & 0 & 10 \\
\hline 13 & -1 & 300 & 0 & 5.5 & 0 & 10 \\
\hline 14 & 1 & 600 & 0 & 5.5 & 0 & 10 \\
\hline 15 & 0 & 450 & 0 & 5.5 & -1 & 4 \\
\hline 16 & 0 & 450 & 0 & 5.5 & 1 & 16 \\
\hline 17 & 0 & 450 & -1 & 1 & 0 & 10 \\
\hline 18 & 0 & 450 & 1 & 10 & 0 & 10 \\
\hline 19 & 1 & 600 & 0 & 5.5 & 1 & 16 \\
\hline 20 & -1 & 300 & 0 & 5.5 & 1 & 16 \\
\hline 21 & 1 & 600 & 0 & 5.5 & -1 & 4 \\
\hline 22 & -1 & 300 & 0 & 5.5 & -1 & 4 \\
\hline
\end{tabular}

* Four replicates at the centre point: runs $9,10,11$ and 12

16 observed in runs $2,4,6,8,9^{*}, 14-19$ and 21 and might be the consequence of the

17 progressive deactivation of the catalyst. All these experiments were conducted at a

18 temperature higher than $450{ }^{\circ} \mathrm{C}$. A decay in the $\mathrm{CC}$ gas with time was also reported in

19 the work of $\mathrm{Hu}$ et al. during the steam reforming of glucose [31]. A comparison

20 between experiments 2 and 4 shows how an increase in the $\mathrm{W} / \mathrm{m}_{\text {lactose }}$ ratio increases the 
1 initial CC gas due to the positive kinetic effect that the catalyst exerts on the process.

2 Furthermore, a greater value of the $\mathrm{W} / \mathrm{m}_{\text {lactose }}$ ratio results in a lessening of the decay of

3 the CC gas over time. This trend is also observed for runs 6 and 8 . However, run 8

4 displays an initial increase in the CC gas followed by a posterior decay. This

5 phenomenon could account for the progressive gasification of the carbonaceous

6 deposits formed by an incomplete vaporisation of the feed, as has been reported in other

7 works dealing with the steam reforming of sugars $[31,32,36]$.

8
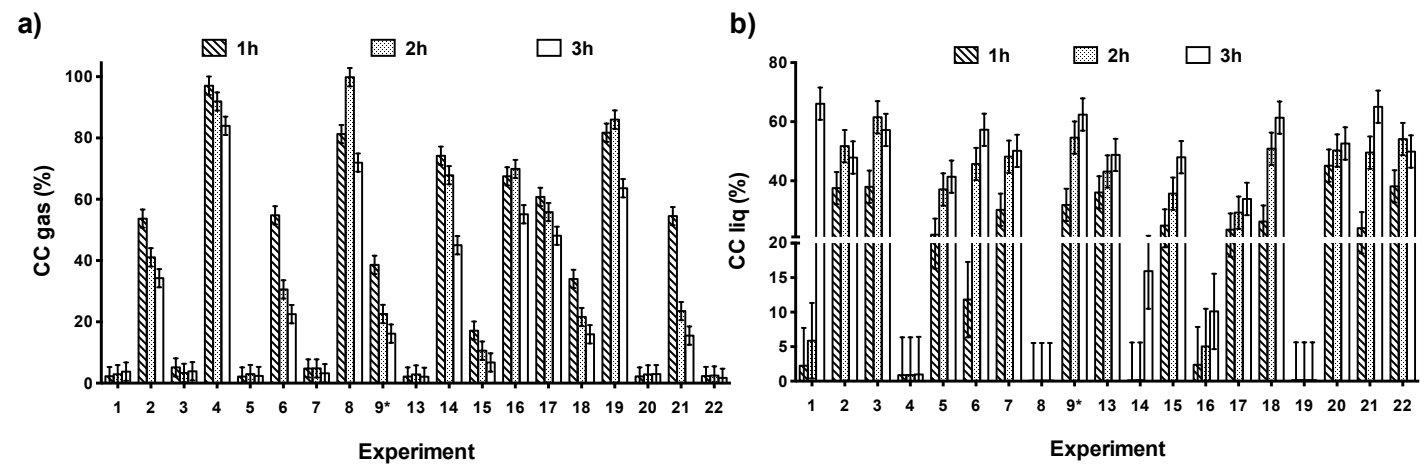

c)

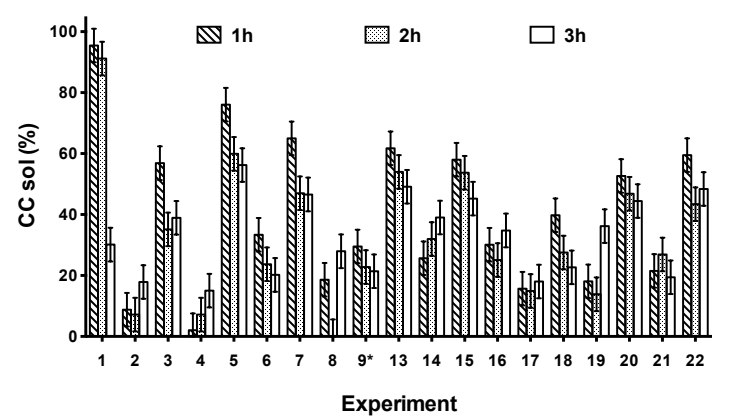

9

Figure 3. Conversion to gas (a), liquid (b) and solid (c) obtained during the reforming

11 experiments. Results are presented as the overall values obtained each 60 minutes and

12 expressed as mean \pm 0.5 Fisher LSD intervals with 95\% confidence.

14 The effect of the lactose concentration is seen when comparing runs 2 with 6 and 4 with

158 . An increase in the concentration of lactose decreases the excess of water, and 
1 consequently the $\mathrm{S} / \mathrm{C}$ ratio. This decreases the reaction rate of the gasification reactions

2 of the carbonaceous deposits and increases the reduction over time of the CC gas.

3 Similar trends have been reported during the steam reforming of xylose, glucose and

$4 \quad$ sucrose $[31,32]$.

6 Runs 1, 3, 5, 7, 13, 20 and 22 display a steady and low $\mathrm{CC}$ gas $(<5 \%)$. All these

7 experiments were conducted at $300{ }^{\circ} \mathrm{C}$ using different lactose concentrations and

$8 \mathrm{~W} / \mathrm{m}_{\text {lactose }}$ ratios. These results indicate that gas production is not favoured at low

9 temperatures. Under these conditions, the lactose concentration and $\mathrm{W} / \mathrm{m}_{\text {lactose }}$ ratio do

10 not exert a significant influence on the CC gas due to the endothermicity of the

11 reforming reactions.

13 The CC sol displays increases and decreases with time. On the one hand, for runs

14 conducted at $300{ }^{\circ} \mathrm{C}(1,3,5,7,13,20$ and 22) the $\mathrm{CC}$ sol is high at the start of the

15 experiment and progressively decreases with time. Sugar molecules are unstable at the

16 temperatures of this process and quickly decompose through pyrolysis, leading to the

17 formation of char particles and gases [32]. The accumulation of this char in the upper

18 part of the reactor might have a positive catalytic effect on lactose pyrolysis and/or

19 cracking reactions. Char obtained from the pyrolysis of different biomass materials has

20 been reported to have catalytic activity for the reforming and cracking of different

21 hydrocarbons [43-49], which accounts for the drops over time observed for the CC sol

$22[31,32]$ and the increases in the CC liq. 
1 Conversely, for runs conducted at higher temperatures $\left(450-600{ }^{\circ} \mathrm{C}\right)$, where the

2 vaporisation of the solution is more favoured and carbon deposits can be removed by

3 gasification due to the relatively high temperature and high $\mathrm{S} / \mathrm{C}$ ratio of the feed, the $\mathrm{CC}$

4 sol increases or remains steady over time. The increases are the consequence of the

5 progressive deactivation of the catalyst, which originates a decrease in the $\mathrm{CC}$ gas and

6 an increase in the $\mathrm{CC}$ sol $[31,32]$. In addition, the accumulation of char particles in the

7 upper part of the reactor hinders the vaporisation of the feed as the atomisation system

8 is not as effective when the liquid comes into contact with solid particles, leading to

9 bigger droplet sizes. Consequently, the evaporation takes places at lower heating rates.

10 This enhances the formation of more carbonaceous deposits, augmenting the formation

11 of char over time, which increases the $\mathrm{CC}$ sol [50]. However these variations do not

12 take place in runs 16,17 and 21, where a steady CC sol is obtained. These runs were

13 conducted using a high $\mathrm{W} / \mathrm{m}_{\text {lactose }}$ ratio and a medium lactose concentration (run 16 ), an

14 intermediate $\mathrm{W} / \mathrm{m}_{\text {lactose }}$ ratio and a low lactose solution (run 17) and high temperature

15 and an intermediate lactose concentration (run 21). These conditions reach a

16 compromise between carbon deposit formation and elimination that can provide a

17 steady evolution for the CC sol.

19 As regards the evolution over time for the CC liq, increases with time are observed for 20 the vast majority of experiments. These increases have two different backgrounds. On

21 the one hand, for the experiments with an initial high CC gas $(2,6,9 *, 14-18)$, the

22 increase in the CC liq accounts for the progressive deactivation of the catalyst, which is

23 not able to completely transform the organic content of the feed into gas, thus increasing

24 the proportion of intermediate liquid products originating from thermal decomposition

25 and incomplete reforming. On the other hand, for the experiments with both an initial 
1 low $\mathrm{CC}$ gas and a high $\mathrm{CC}$ sol $(1,3,5,7,13,20$ and 22), the increases might be the

2 consequence of the formation of liquid condensable products from the progressive

3 pyrolysis of the feed and or/the carbon deposits (mainly as char), thus increasing the CC

$4 \quad$ liq over time.

6 Interestingly, experiments 4, 8 and 19, which were conducted at a high temperature

$7 \quad\left(600{ }^{\circ} \mathrm{C}\right)$ and high spatial time (16 g catalyst $\mathrm{min} / \mathrm{g}$ lactose), display negligible CC liq

8 and a relatively high amount of $\mathrm{CC}$ gas regardless of the lactose concentration. The

9 COD values for 1, 5.5 and $10 \mathrm{wt} . \%$ lactose solutions are $11.5,63.5$ and $115.5 \mathrm{~kg} / \mathrm{m}^{3}$,

10 respectively. The liquid condensate obtained in experiments 4,8 and $19(1,10$ and 5.5

11 wt.\% of lactose, respectively) has COD values of $3.29,4.60$ and $1.59 \mathrm{~kg} / \mathrm{m}^{3}$,

12 respectively. This corresponds to a reduction in the COD of the solutions of 71, 96 and

$1397 \%$, respectively, with respect to the original feedstock. Therefore, high temperatures

14 and spatial times enhance gas formation from the vaporised part of the feed, thus

15 producing an almost carbon free liquid condensate with a considerably lower COD than

16 that of the original feedstock.

18 To gain a better insight into the carbon deposition, the carbon deposited on the used 19 catalysts was examined and the solid carbon distribution between char and coke was 20 calculated. Table 5 lists the $\mathrm{CC}$ coke, $\mathrm{CC}$ char and the amount of $\mathrm{C}$ deposited on the 21 catalysts during the reforming experiments. The results indicate that the vast majority of 22 the $\mathrm{CC}$ sol is due to the formation of char. In general more than $80 \%$ of the total solid $\mathrm{C}$ 23 is due to char formation. This proportion increases up to $90 \%$ for the experiments 24 conducted at $300{ }^{\circ} \mathrm{C}$, confirming the significant formation of carbonaceous solid at low 
1 temperatures. Char production is highly likely to occur during the thermal

2 decomposition of lactose. Lactose is unstable when heated at the temperatures

3 employed in this work and it decomposes before reaching the catalytic bed, resulting in

4 severe char formation in the upper part of the reactor. This tendency of sugars to

5 decompose giving char has also been reported for xylose, glucose and sucrose [31, 32].

6 The statistical analysis of the amount of carbon (expressed as $\mathrm{mg} \mathrm{C} / \mathrm{g}$ catalyst $\mathrm{g}$ lactose

7 reacted to produce gases) reveals that the highest deposition takes place at $300{ }^{\circ} \mathrm{C}$

8 (groups A to G). Furthermore, a relatively high amount of this carbon is deposited on

9 the catalyst surface, proving evidence for the experimentally observed catalyst

10 deactivation. This catalyst deactivation by coking has been reported in other works

11 dealing with the steam reforming of other oxygenated compounds. A very detailed

12 mechanism for coke deposition, explaining the deactivation of Ni-based catalysts by

13 coking, is provided in the work of Wang et al. [51].

15 Table 5. Solid carbon distribution. Overall 3 hours carbon conversion to solid, char 16 and coke and $C$ deposited on the catalyst.

17

\begin{tabular}{lllll}
\hline Run & CC solid (\%) & CC char (\%) & CC coke (\%) & C (mg C/g cat. g org.) \\
\hline 1 & $72.27^{\mathrm{A}}$ & $70.83^{\mathrm{A}}$ & $1.44^{\mathrm{H}}$ & $39.84^{\mathrm{A}}$ \\
2 & $11.28^{\mathrm{K}, \mathrm{L}}$ & $10.67^{\mathrm{L}}$ & $0.61^{\mathrm{I}}$ & $1.21^{\mathrm{I}}$ \\
3 & $43.64^{\mathrm{F}}$ & $39.54^{\mathrm{F}}$ & $4.10^{\mathrm{C}}$ & $21.50^{\mathrm{D}}$ \\
4 & $8.10^{\mathrm{L}}$ & $6.01^{\mathrm{M}}$ & $2.09^{\mathrm{F}, \mathrm{G}}$ & $0.51^{\mathrm{L}, \mathrm{M}, \mathrm{N}}$ \\
5 & $64.08^{\mathrm{B}}$ & $62.20^{\mathrm{B}}$ & $1.88^{\mathrm{F}, \mathrm{G}, \mathrm{H}}$ & $25.09^{\mathrm{C}}$ \\
6 & $25.76^{\mathrm{H}, \mathrm{I}}$ & $22.84^{\mathrm{H}, \mathrm{I}}$ & $2.93^{\mathrm{E}}$ & $0.68^{\mathrm{J}, \mathrm{K}, \mathrm{L}}$ \\
7 & $52.86^{\mathrm{C}, \mathrm{D}}$ & $47.17^{\mathrm{E}}$ & $5.69^{\mathrm{B}}$ & $11.03^{\mathrm{G}}$ \\
8 & $15.55^{\mathrm{J}, \mathrm{K}}$ & $9.03^{\mathrm{L}, \mathrm{M}}$ & $6.52^{\mathrm{A}}$ & $0.16^{\mathrm{N}}$ \\
$9 *$ & $25.06^{ \pm} 0.98^{\mathrm{I}}$ & $24.55^{ \pm} 0.72^{\mathrm{J}}$ & $0.51^{ \pm} 0.12^{\mathrm{D}}$ & $0.84^{\mathrm{M}} 0.08^{\mathrm{J}, \mathrm{K}}$ \\
13 & $54.96^{\mathrm{C}}$ & $51.58^{\mathrm{C}}$ & $3.37^{\mathrm{D}, \mathrm{E}}$ & $18.17^{\mathrm{F}}$ \\
14 & $30.00^{\mathrm{G} \mathrm{H}}$ & $25.87^{\mathrm{G}, \mathrm{H}}$ & $4.13^{\mathrm{C}}$ & $0.58^{\mathrm{K}, \mathrm{L}, \mathrm{M}}$ \\
15 & $52.32^{\mathrm{C}, \mathrm{D}, \mathrm{E}}$ & $50.79^{\mathrm{C}, \mathrm{D}}$ & $1.53^{\mathrm{H}}$ & $4.15^{\mathrm{H}}$ \\
16 & $29.99^{\mathrm{G}, \mathrm{H}}$ & $26.10^{\mathrm{G}}$ & $3.89^{\mathrm{C}, \mathrm{D}}$ & $0.23^{\mathrm{M}, \mathrm{N}}$ \\
17 & $16.21^{\mathrm{J}}$ & $14.53^{\mathrm{K}}$ & $1.68^{\mathrm{G}, \mathrm{H}}$ & $1.01^{\mathrm{I}, \mathrm{J}}$ \\
18 & $32.24^{\mathrm{G}}$ & $26.17^{\mathrm{G}}$ & $6.07^{\mathrm{A}, \mathrm{B}}$ & $0.59^{\mathrm{K}, \mathrm{L}, \mathrm{M}}$ \\
19 & $22.72^{\mathrm{I}}$ & $16.32^{\mathrm{K}}$ & $6.40^{\mathrm{A}}$ & $0.32^{\mathrm{L}, \mathrm{M}, \mathrm{N}}$ \\
20 & $47.98^{\mathrm{E}, \mathrm{F}}$ & $41.49^{\mathrm{F}}$ & $6.49^{\mathrm{A}}$ & $19.65^{\mathrm{E}}$ \\
21 & $22.62^{\mathrm{I}}$ & $20.22^{\mathrm{I}, \mathrm{J}}$ & $2.40^{\mathrm{F}}$ & $1.20^{\mathrm{I}}$ \\
22 & $50.43^{\mathrm{D}, \mathrm{E}}$ & $48.21^{\mathrm{D}, \mathrm{E}}$ & $2.21^{\mathrm{F}}$ & $32.91^{\mathrm{B}}$ \\
\hline
\end{tabular}

19 Letters in each column represent LSD statistically significant groups with $95 \%$ confidence according to the ANOVA analysis. 
2 The specific effect of the operating conditions as well as their possible interactions on

3 the process has been studied using the results obtained during the first 60 minutes of

4 reaction. The models created in terms of codec factors considering the ANOVA analysis

5 of the experiments performed (Table 4) are presented in Table 6. The reaction

6 temperature is the operating variable with the highest influence on the $\mathrm{CC}$ gas and $\mathrm{CC}$

7 sol. An increase in the temperature increases and decreases the $\mathrm{CC}$ gas (positive term in

8 the model) and CC sol (negative term in the model), respectively. An increase in the

9 temperature not only facilitates the vaporisation of the feed, decreasing the formation of

10 solid carbon, but also favours the reforming process due to its endothermic nature [31,

$1132]$. Furthermore, the effect of the temperature depends on the $\mathrm{W} / \mathrm{m}_{\text {lactose }}$ ratio due to the

12 significant interaction between these two variables. The $\mathrm{CC}$ liq is significantly

13 influenced by the temperature and $\mathrm{W} / \mathrm{m}_{\text {lactose }}$ ratio. An increase in the temperature

14 decreases the CC liq (negative term in the model) due to the positive effect that the

15 temperature exerts on the gas production from the intermediate liquid compounds

16 resulting from the thermal decomposition of lactose.

18 Table 6. Relative influence of the operating conditions on the CC gas, CC liq and CC

19 sol according to the ANOVA analysis for the first hour of reaction.

\begin{tabular}{|c|c|c|c|c|c|c|c|c|c|c|c|c|c|c|c|c|c|c|}
\hline Variable & $\overline{\mathbf{R}^{2}}$ & I. Term & $T$ & $\mathbf{W}$ & $\mathrm{C}$ & TW & TC & WC & TWC & $\mathbf{T}^{2}$ & $\mathbf{W}^{2}$ & $\mathrm{C}^{2}$ & $\mathbf{T}^{2} \mathbf{W}$ & $\mathbf{T}^{2} \mathbf{C}$ & TW $^{2}$ & $\mathbf{T C}^{2}$ & $\mathbf{W C}^{2}$ & TWC $^{2}$ \\
\hline $\begin{array}{l}\text { CC gas } \\
(\%)\end{array}$ & 0.98 & 38.6 & $\begin{array}{l}34.01 \\
(52)\end{array}$ & $\begin{array}{l}25.18 \\
(17)\end{array}$ & $\begin{array}{l}-13.39 \\
(5)\end{array}$ & $\begin{array}{l}7.64 \\
(11)\end{array}$ & ns & ns & ns & ns & ns & ns & $\begin{array}{l}-16.64 \\
(9)\end{array}$ & $\begin{array}{l}11.5 \\
(6)\end{array}$ & ns & ns & Ns & ns \\
\hline $\begin{array}{l}\text { CC liq } \\
(\%)\end{array}$ & 0.95 & 30.72 & $\begin{array}{l}-15.85 \\
(22)\end{array}$ & $\begin{array}{l}-11.24 \\
(7)\end{array}$ & ns & $\begin{array}{l}-10.28 \\
(22)\end{array}$ & $\begin{array}{l}-4.78 \\
(8)\end{array}$ & ns & $\begin{array}{l}6.53 \\
(11)\end{array}$ & ns & $\begin{array}{l}-11.97 \\
(9)\end{array}$ & ns & $\begin{array}{l}9.49 \\
(8)\end{array}$ & ns & ns & $\begin{array}{l}10.61 \\
(12)\end{array}$ & Ns & ns \\
\hline $\begin{array}{l}\text { CC sol } \\
(\%)\end{array}$ & 0.99 & 26.74 & $\begin{array}{l}-18.1 \\
(35) \\
\end{array}$ & $\begin{array}{l}-13.94 \\
(11)\end{array}$ & $\begin{array}{l}12.04 \\
(7)\end{array}$ & ns & $\begin{array}{l}6.56 \\
(7) \\
\end{array}$ & ns & $\begin{array}{l}-4.45 \\
(5)\end{array}$ & $\begin{array}{l}10.21 \\
(8)\end{array}$ & $\begin{array}{l}10.55 \\
(4)\end{array}$ & $\begin{array}{l}-5.77 \\
(0.1) \\
\end{array}$ & $\begin{array}{l}11.37 \\
(4)\end{array}$ & $\begin{array}{l}-8.3 \\
(4) \\
\end{array}$ & ns & $\begin{array}{l}-10.71 \\
(8)\end{array}$ & $\begin{array}{l}-6.32 \\
(4)\end{array}$ & $\begin{array}{l}3.53 \\
(4) \\
\end{array}$ \\
\hline
\end{tabular}


1 The effects of the operating variables on the $\mathrm{CC}$ gas, $\mathrm{CC}$ liq and $\mathrm{CC}$ sol are shown in

2 Figure 4. The evolution of these variables was obtained from the ANOVA analysis

3 (Table 6) of all the experiments performed (Table 4). In addition, when possible, some

4 experimental points were added. Specifically, Figures $4 \mathrm{a}$ and $\mathrm{b}$ show the effect on the

$5 \mathrm{CC}$ gas of the temperature for $\mathrm{W} / \mathrm{m}_{\text {lactose }}$ ratios of 4 and $16 \mathrm{~g}$ catalyst $\mathrm{min} / \mathrm{g}$ lactose when

61 and $10 \mathrm{wt} . \%$ lactose solutions were used, respectively. Figures $4 \mathrm{c}$ and $\mathrm{d}$ and $\mathrm{e}$ and $\mathrm{f}$

7 illustrate these effects for the $\mathrm{CC}$ liq and $\mathrm{CC}$ sol, respectively. In general, the $\mathrm{CC}$ gas

8 and $\mathrm{CC}$ sol show opposite trends. An increase in the temperature augments the CC gas

9 and reduces the $\mathrm{CC}$ sol, as discussed above.
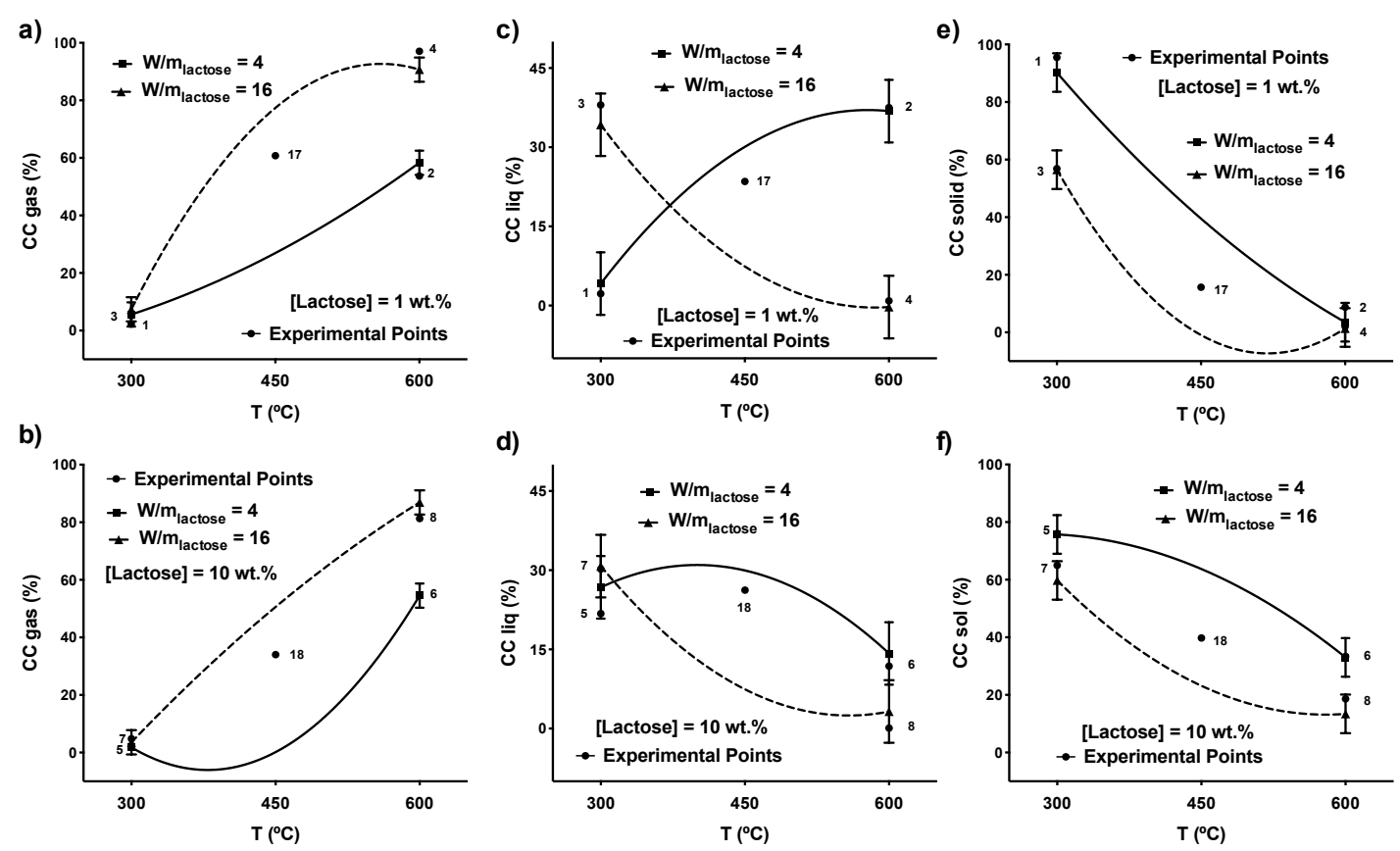

11 Figure 4. Interaction plots for the initial CC gas ( $a$ and b) and CC liq (c and d) and CC

12 sol (e and f). Bars are LSD intervals with 95\% confidence.

14 With respect to the effect of the $\mathrm{W} / \mathrm{m}_{\text {lactose }}$ ratio, an increase from 4 to $16 \mathrm{~g}$ catalyst

$15 \mathrm{~min} / \mathrm{g}$ lactose increases the $\mathrm{CC}$ gas and decreases the $\mathrm{CC}$ sol due to the positive catalytic 
1 effect the catalyst has on the reforming reaction and the pyrolysis and gasification of

2 solid deposits $[31,32]$. However, this increment depends on the temperature and lactose

3 concentration. At temperatures between 300 and $350{ }^{\circ} \mathrm{C}$, an increase in the $\mathrm{W} / \mathrm{m}_{\text {lactose }}$

4 ratio from 4 to $16 \mathrm{~g}$ catalyst $\mathrm{min} / \mathrm{g}$ lactose does not have a statistically significant

5 influence on the CC gas. Within this temperature range, the vaporisation of the feed is

6 not favoured and the vast majority of the organics are converted into carbonaceous

7 deposits or liquid intermediates. Therefore an increment in the amount of catalyst

$8\left(\mathrm{~W} / \mathrm{m}_{\text {lactose }}\right.$ ratio $)$ does not have a significant influence on the $\mathrm{CC}$ gas.

10 Conversely, as the temperature increases and the formation of gas is most favoured, an

11 increase in the $\mathrm{W} / \mathrm{m}_{\text {lactose }}$ ratio significantly augments the $\mathrm{CC}$ gas. An almost complete

$12 \mathrm{CC}$ gas can be achieved at temperatures higher than $500^{\circ} \mathrm{C}$ when a $1 \mathrm{wt} . \%$ lactose

13 solution is fed. This increment in the $\mathrm{W} / \mathrm{m}_{\text {lactose }}$ ratio diminishes the $\mathrm{CC}$ solid regardless

14 of the temperature. However, this drop depends on the concentration of lactose and the $15 \mathrm{~W} / \mathrm{m}_{\text {lactose }}$ ratio.

17 The effect of the concentration of lactose can be gathered comparing Figures $4 \mathrm{a}$ with $\mathrm{b}$ 18 and e with $\mathrm{f}$. An increase in the concentration of lactose in the solution from 1 to 10 19 wt. \% reduces the $\mathrm{CC}$ gas between 350 and $550{ }^{\circ} \mathrm{C}$, as explained above. As the lactose 20 concentration increases, the formation of carbonaceous deposits obtained from an 21 incomplete vaporisation of the feed is most favoured due to the reduction of the $\mathrm{S} / \mathrm{C}$ 22 ratio (157 and $14 \mathrm{~mol} \mathrm{H}_{2} \mathrm{O} / \mathrm{mol} \mathrm{C}$ for 1 and $10 \mathrm{wt} . \%$ lactose solutions, respectively) that 23 lowers the excess of water. The excess of water in the feed not only helps the 24 vaporisation of lactose but also helps the conversion of the carbonaceous deposits to 
1 take place. Hu et al. [31] reported these trends when increasing the $\mathrm{S} / \mathrm{C}$ ratio from 3 to 9

$2 \mathrm{~mol} \mathrm{H}_{2} \mathrm{O} / \mathrm{mol} \mathrm{C}$ during the steam reforming of glucose and concluded that at high $\mathrm{S} / \mathrm{C}$

3 ratios the high partial pressure of steam in the reactor favours char removal by

4 gasification and promotes the adsorption of steam on the active sites of the catalyst,

5 helping to reduce coke formation. Marquevich et al. [32] found an increase in gas

6 production together with a decrease in solid formation during the steam reforming of

7 glucose and xylose when increasing the S/C ratio from 7 to 47 and 14 to $37 \mathrm{~mol}$

$8 \mathrm{H}_{2} \mathrm{O} / \mathrm{mol} \mathrm{C}$, respectively.

10 Employing a $\mathrm{W} / \mathrm{m}_{\text {lactose }}$ ratio of $16 \mathrm{~g}$ catalyst $\mathrm{min} / \mathrm{g}$ lactose, a complete $\mathrm{CC}$ gas can be

11 obtained at temperatures higher than 500 and $600{ }^{\circ} \mathrm{C}$ when lactose solutions of 1 and 10

12 wt. \% are fed, respectively. This increase in the concentration of lactose increases the

$13 \mathrm{CC}$ sol for the whole range of temperatures studied in this work except for temperatures

14 lower than $350{ }^{\circ} \mathrm{C}$, where the formation of carbonaceous deposits is similar.

16 The effect of the temperature on the CC liq depends on the lactose concentration and

$17 \mathrm{~W} / \mathrm{m}_{\text {lactose }}$ ratio, since a significant interaction between these variables was detected. For

18 a 1 wt.\% lactose solution, an increase in the temperature between 300 and $600{ }^{\circ} \mathrm{C}$ has

19 two different effects depending on the $\mathrm{W} / \mathrm{m}_{\text {lactose }}$ ratio. On the one hand, when a

$20 \mathrm{~W} / \mathrm{m}_{\text {lactose }}$ ratio of $4 \mathrm{~g}$ catalyst $\mathrm{min} / \mathrm{g}$ lactose is used, the $\mathrm{CC}$ liq increases as the

21 temperature increases. However, the opposite trend is found when a $\mathrm{W} / \mathrm{m}_{\text {lactose }}$ ratio of

$2216 \mathrm{~g}$ catalyst is used. This increase in temperature favours the reforming process,

23 decreasing the $\mathrm{CC}$ sol. However, when a low amount of catalyst is used the $\mathrm{CC}$ liq

24 increases, since this amount of catalyst in the bed may be insufficient for a complete 
1 conversion of the organics of the feed (lactose and its decomposition products) into

2 gases, thus increasing the production of intermediate liquids. However, when a higher

3 amount of catalyst is used, the reaction rate of the reforming reactions towards gas

4 production increases and therefore both the $\mathrm{CC}$ sol and CC liq decrease.

6 The effect of the concentration of lactose on the CC liq can be seen when comparing

7 Figure $4 \mathrm{c}$ with $3 \mathrm{~d}$. This effect depends on the $\mathrm{W} / \mathrm{m}_{\text {lactose }}$ ratio. When a $\mathrm{W} / \mathrm{m}_{\text {lactose }}$ ratio

8 of $4 \mathrm{~g}$ catalyst $\mathrm{min} / \mathrm{g}$ lactose is used, two different tendencies are found for the CC liq,

9 depending on the temperature. For temperatures lower than $450{ }^{\circ} \mathrm{C}$, an increase in the

10 lactose concentration augments the $\mathrm{CC}$ liq. At this temperature range, the reforming

11 process is not favoured. In addition, this increase in the lactose concentration reduces

12 the excess of water of the feed, leading to a lower extension of the reforming reactions

13 and thus increasing the $\mathrm{CC}$ liq. In contrast, at temperatures higher than $450{ }^{\circ} \mathrm{C}$ the same

14 increment in the concentration of lactose reduces the $\mathrm{CC}$ liq. At these temperatures, the

$15 \mathrm{CC}$ sol is lower for a $1 \mathrm{wt} . \%$ than for a10 wt.\% solution. This drop in the CC sol

16 enhances the formation of intermediate liquid products, increasing the $\mathrm{CC}$ liq.

\subsubsection{Gas composition}

19 Figure 5 shows the gas composition obtained for the different experiments. The gas

20 phase consists of a mixture of $\mathrm{H}_{2}$ (0-70 vol.\%), $\mathrm{CO}_{2}(20-70$ vol.), $\mathrm{CO}$ (2-34 vol.\%) and

$21 \mathrm{CH}_{4}(0-2.4$ vol.\%). Statistically significant $(\mathrm{p}$-values $<0.05)$ variations are observed for

22 the gas composition between experiments and intervals of the same experiment. 
1 The highest variations with time for the relative amounts of $\mathrm{H}_{2}$ and $\mathrm{CO}_{2}$ in the gas are

2 observed for runs conducted at $300{ }^{\circ} \mathrm{C}(3,5,7,13,20$ and 22), where the proportions of

$3 \quad \mathrm{H}_{2}$ and $\mathrm{CO}_{2}$ in the gas decrease and increase, respectively. These experiments were

4 conducted at the lowest temperature employed in this work $\left(300^{\circ} \mathrm{C}\right)$, and where the

5 greatest amount of coke was deposited on the used catalysts (more than $11 \mathrm{mg} \mathrm{C} / \mathrm{g}$

6 catalyst g organic reacted). This accounts for the catalyst deactivation by coking and

7 indicates that the temperature exerts a significant influence on catalyst deactivation. The

8 temperature significantly influences the reforming process, increasing the reaction rate

9 of the reforming reactions, thus partially compensating for the catalyst deactivation.

a)

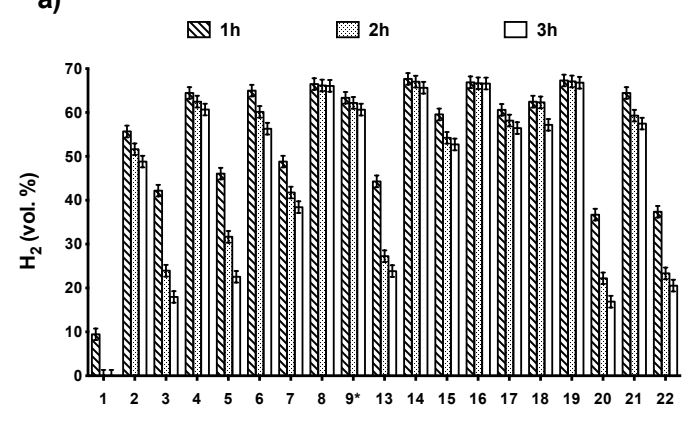

Experiment

c)

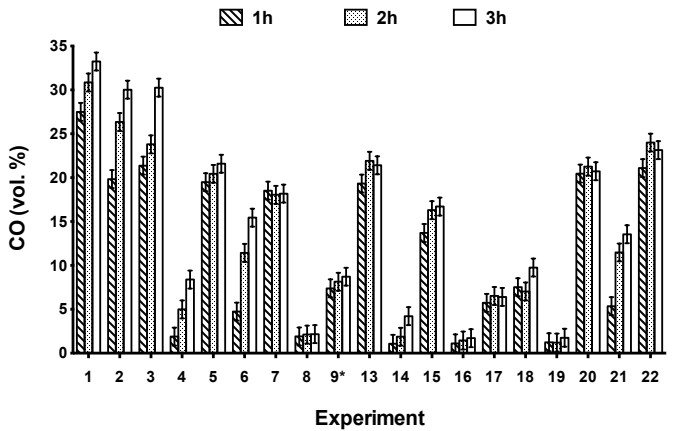

b)

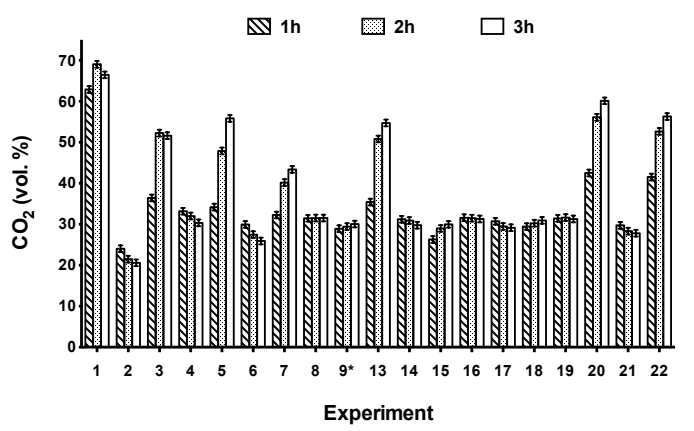

d)

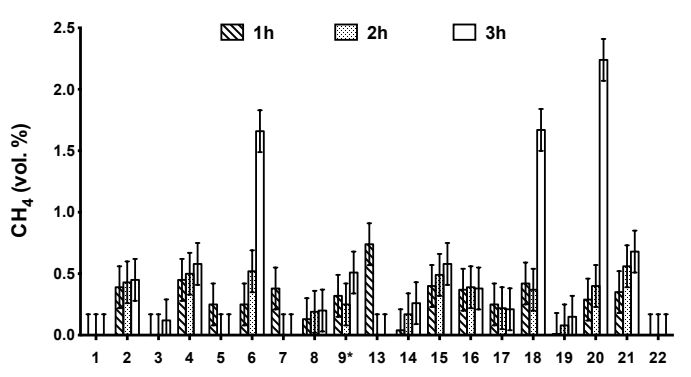

Experiment

11 Figure 5. Concentration (vol.\%) of $\mathrm{H}_{2}(a), \mathrm{CO}_{2}(b) \mathrm{CO}(c)$ and $\mathrm{CH}_{4}(d)$ in the gas.

12 Results are presented as the overall values obtained each 60 minutes and expressed as mean \pm 0.5 Fisher LSD intervals with 95\% confidence. 
1 In addition, during the reforming process an initial thermal decomposition of the

2 organic compounds might occur before reaching the catalytic bed. This produces gases

3 (mainly $\mathrm{H}_{2}, \mathrm{CO}, \mathrm{CO}_{2}$ and $\mathrm{CH}_{4}$ ), other intermediate or decomposition products and char

4 [32]. The gases and the intermediate products evolve towards achieving the

5 thermodynamic composition for the gas when passing through the catalytic bed, which

6 results in an increase and a decrease in the proportions of $\mathrm{H}_{2}$ and $\mathrm{CO}_{2}$, respectively.

7

8 Comparing the experiments conducted at the same temperature, the lower the $\mathrm{W} / \mathrm{m}_{\text {lactose }}$

9 ratio, the higher are the reductions with time in the proportion of $\mathrm{H}_{2}$. High $\mathrm{W} / \mathrm{m}_{\text {lactose }}$

10 ratios allow having a greater amount of active catalyst in the bed, thus minimising the

11 decay observed for the proportion of $\mathrm{H}_{2}$ in the gas. This finding can be appreciated by

12 comparing the following experiments: 2 and 4; 6 and 8; and 9, 15 and 16.

14 Some variations with time are observed for the proportions of $\mathrm{CO}$ and $\mathrm{CH}_{4}$ in the gas.

15 The proportion of $\mathrm{CO}$ increases with time due to the progressive deactivation of the

16 catalyst and the lesser shift of the WGS reaction towards $\mathrm{H}_{2}$ and $\mathrm{CO}_{2}$. The greatest

17 increases in the proportion of $\mathrm{CO}$ occur at low temperatures, where the highest

18 deactivation of the catalyst is observed. An exception to this occurs in experiment 3 ,

19 where the decrease in the proportion of $\mathrm{H}_{2}$ is accompanied by an increase in both the

20 proportions of $\mathrm{CO}$ and $\mathrm{CO}_{2}$, probably due to the decrease over time observed in the

21 evolution of the $\mathrm{CC}$ sol, which slightly increases the amount of $\mathrm{C}$ in the gas. The

22 proportion of $\mathrm{CH}_{4}$ in the gas remains steady with time for the vast majority of the

23 experiments. 
1 The specific effects of the operating conditions as well as their possible interactions on

2 the volumetric composition of the gas were studied considering the results obtained

3 during the first 60 minutes of reaction. Table 7 lists the results of the statistical analyses.

4 The temperature (linear and quadratic terms) is the operating variable exerting the

5 highest influence on the proportions of $\mathrm{H}_{2}, \mathrm{CO}_{2}$ and $\mathrm{CO}$ in the gas (relative importance

6 of $31 \%, 19 \%$ and $31 \%$, respectively). The interaction between the temperature and the

7 quadratic term for the $\mathrm{W} / \mathrm{m}_{\text {lactose }}$ ratio has the highest influence $(21 \%)$ on the

8 concentration of $\mathrm{CH}_{4}$ in the gas. The coefficients of the codec models show how an

9 increase in the temperature increases the concentration of $\mathrm{H}_{2}$ in the gas (positive term)

10 while reducing the proportion of the other gases (negative term). The concentration of

11 lactose individually does not influence the gas composition. However, significant

12 interactions with the temperature and the $\mathrm{W} / \mathrm{m}_{\text {lactose }}$ ratio are detected.

14 Table 7. Relative influence of the operating conditions on the gas composition

15 according to the ANOVA analysis for the first hour of reaction

\begin{tabular}{|c|c|c|c|c|c|c|c|c|c|c|c|c|c|c|c|c|c|c|}
\hline Variable & $\mathbf{R}^{2}$ & I. Term & $T$ & $\mathbf{W}$ & $\mathrm{C}$ & TW & TC & WC & TWC & $T^{2}$ & $\mathbf{W}^{2}$ & $\mathrm{C}^{2}$ & $T^{2} W$ & $\mathrm{~T}^{2} \mathrm{C}$ & $T^{T W^{2}}$ & TC $^{2}$ & $\mathrm{WC}^{2}$ & $\mathrm{TWC}^{2}$ \\
\hline $\begin{array}{l}\mathrm{H}_{2} \\
\text { (vol.\%) }\end{array}$ & 0.99 & 62.8 & $\begin{array}{l}13.29 \\
(31)\end{array}$ & ns & ns & ns & $\begin{array}{l}-3.99 \\
(7)\end{array}$ & $\begin{array}{l}-4.66 \\
(8)\end{array}$ & $\begin{array}{l}2.84 \\
(5)\end{array}$ & $\begin{array}{l}-9.32 \\
(17)\end{array}$ & $\mathrm{ns}$ & $\begin{array}{l}-3.75 \\
(4)\end{array}$ & ns & $\begin{array}{l}6.83 \\
(12)\end{array}$ & ns & ns & $\begin{array}{l}5.73 \\
(10)\end{array}$ & $\begin{array}{l}-3.15 \\
(6)\end{array}$ \\
\hline $\begin{array}{l}\mathrm{CO}_{2} \\
\text { (vol.\%) }\end{array}$ & 0.99 & 29.69 & $\begin{array}{l}-2.1 \\
(19)\end{array}$ & $\begin{array}{l}2.65 \\
(2)\end{array}$ & ns & ns & $\begin{array}{l}4.63 \\
(12)\end{array}$ & $\begin{array}{l}2.11 \\
(6)\end{array}$ & $\begin{array}{l}-4.02 \\
(11)\end{array}$ & $\begin{array}{l}4.87 \\
(13)\end{array}$ & ns & $\begin{array}{l}1.64 \\
\text { (1) }\end{array}$ & $\begin{array}{l}-1.97 \\
(5)\end{array}$ & $\begin{array}{l}-3.58 \\
(9)\end{array}$ & $\begin{array}{l}-3.74 \\
(5)\end{array}$ & ns & $\begin{array}{l}-2.89 \\
(4)\end{array}$ & $\begin{array}{l}4.88 \\
(13)\end{array}$ \\
\hline $\begin{array}{l}\text { CO } \\
\text { (vol.\%) }\end{array}$ & 0.99 & 6.25 & $\begin{array}{l}-8.87 \\
(31)\end{array}$ & $\begin{array}{l}-6.29 \\
(13)\end{array}$ & ns & $\begin{array}{l}-1.43 \\
(5)\end{array}$ & ns & $\begin{array}{l}2.53 \\
(8)\end{array}$ & $\begin{array}{l}1.25 \\
(4)\end{array}$ & $\begin{array}{l}4.75 \\
(14)\end{array}$ & $\begin{array}{l}1.96 \\
(4)\end{array}$ & ns & $\begin{array}{l}5.1 \\
(5)\end{array}$ & $\begin{array}{l}-3.24 \\
(10)\end{array}$ & ns & $\begin{array}{l}1.56 \\
(3)\end{array}$ & $\begin{array}{l}-2.3 \\
(4)\end{array}$ & Ns \\
\hline $\begin{array}{l}\mathrm{CH}_{4} \\
\text { (vol.\%) }\end{array}$ & 0.99 & 0.29 & $\begin{array}{l}-0.35 \\
(1)\end{array}$ & ns & $\begin{array}{l}0.09 \\
(5)\end{array}$ & $\begin{array}{l}-0.16 \\
(12)\end{array}$ & $\begin{array}{l}-0.14 \\
(19)\end{array}$ & ns & $\begin{array}{l}-0.04 \\
(6)\end{array}$ & Ns & ns & $\begin{array}{l}-0.08 \\
(4)\end{array}$ & ns & $\begin{array}{l}-0.06 \\
(4)\end{array}$ & $\begin{array}{l}0.37 \\
(21)\end{array}$ & $\begin{array}{l}0.06 \\
(17)\end{array}$ & ns & $\begin{array}{l}0.13 \\
(11)\end{array}$ \\
\hline
\end{tabular}

18 ns. Non significant with $95 \%$ confidence

Response variable $=$ Independent term + Coefficient $\mathrm{T} \cdot \mathrm{T}+$ Coefficient $\mathrm{W} \cdot \mathrm{W}+$ Coefficient $\mathrm{C} \cdot \mathrm{C}+\mathrm{Coefficient} \mathrm{TW} \cdot \mathrm{TW}+\mathrm{Coefficient}$ $\mathrm{TC} \cdot \mathrm{TC}+$ Coefficient $\mathrm{WC} \cdot \mathrm{WC}+$ Coefficient $\mathrm{TWC} \cdot \mathrm{TWC}+$ Coefficient $\mathrm{T}^{2} \cdot \mathrm{T}^{2}+$ Coefficient $\mathrm{W}^{2} \cdot \mathrm{W}^{2}+\mathrm{Coefficient}^{2} \cdot \mathrm{C}^{2}+\mathrm{Coefficient}^{2}$

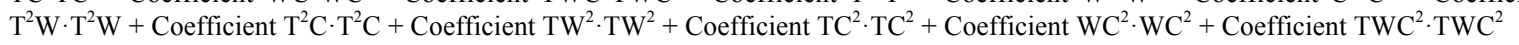

25 The effects of the operating conditions on the composition of the gas obtained with the

26 ANOVA analysis are plotted in Figures 6 and 7. Specifically, Figures 6 a and c show

27 the effect of the temperature using a $1 \mathrm{wt} . \%$ lactose solution and $\mathrm{W} / \mathrm{m}_{\text {glycerol }}$ ratios of 4

28 and $16 \mathrm{~g}$ catalyst $\mathrm{min} / \mathrm{g}$ lactose on the concentrations of $\mathrm{H}_{2}$ and $\mathrm{CO}_{2}$. The influence of 
1 the temperature and the $\mathrm{W} / \mathrm{m}_{\text {glycerol }}$ for a $10 \mathrm{wt} . \%$ lactose solution is shown in Figures 6

$2 \mathrm{~b}$ and d. Figure 7 plots these effects for the concentrations of $\mathrm{CO}$ and $\mathrm{CH}_{4}$ in the gas.

3 The evolution of these variables was obtained from the ANOVA analysis (Table 7) of

4 all the experiments performed (Table 4). In addition, when possible, some experimental 5 points were added.

6

$7 \quad 3.2 .2 .1 \mathrm{H}_{2}$ and $\mathrm{CO}_{2}$

a)

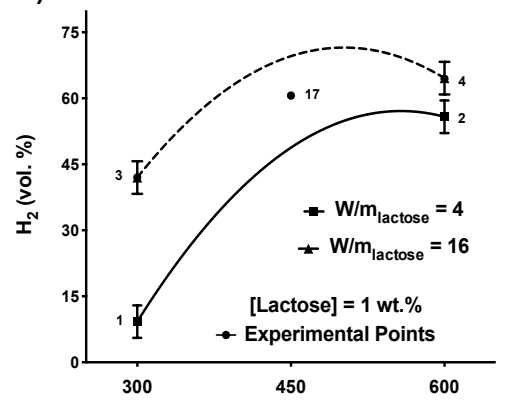

c)

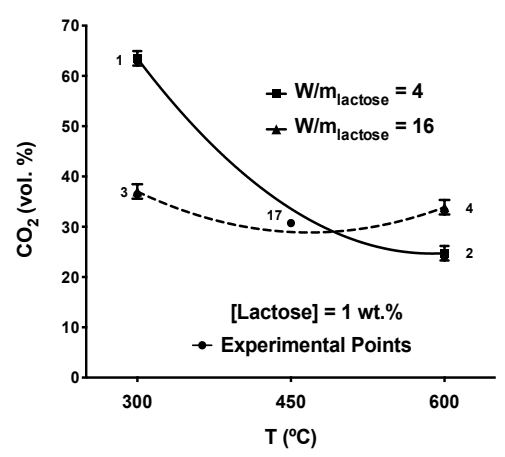

b)

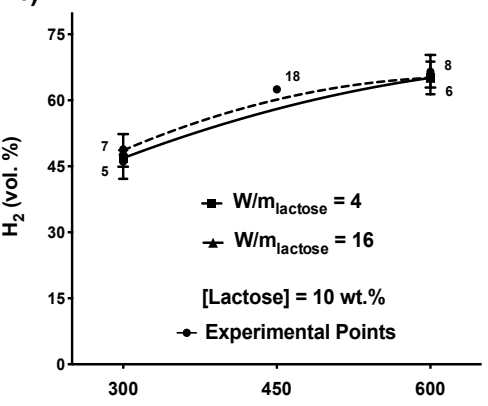

d)

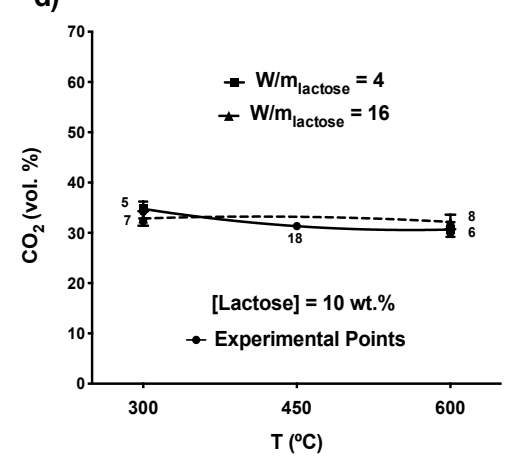

8

9 Figure 6. Interaction plots for initial relative amounts (vol.\%) of $\mathrm{H}_{2}$ (a and b) and $\mathrm{CO}_{2}$

10 (c and d) in the gas. Bars are LSD intervals with 95\% confidence.

12 Figure 6 shows how an increase in the temperature from 300 to $600{ }^{\circ} \mathrm{C}$ increases the

13 concentration of $\mathrm{H}_{2}$ in the gas regardless of the other operating variables and decreases

14 the proportion of $\mathrm{CO}_{2}$ in some cases. This development in the proportion of $\mathrm{H}_{2}$, where

15 an optimum takes place at $450-500{ }^{\circ} \mathrm{C}$, has also been reported in other works dealing 
1 with steam reforming of other saccharides [31,32] and is the consequence of the

2 endothermic character of lactose steam reforming. The temperature exerts the greatest

3 effect on the proportion of these two gases for a $1 \mathrm{wt} . \%$ lactose solution, while its effect

4 is relatively weak as the concentration of lactose increases up to $10 \mathrm{wt} . \%$. As an

5 exception, the temperature does not exert a significant effect on the proportion of $\mathrm{CO}_{2}$

6 for a $1 \mathrm{wt} . \%$ lactose solution using a $\mathrm{W} / \mathrm{m}_{\text {lactose }}$ ratio of $16 \mathrm{~g}$ catalyst $\mathrm{min} / \mathrm{g}$ lactose. This

7 high $\mathrm{W} / \mathrm{m}_{\text {lactose }}$ ratio produces a concentration of $\mathrm{CO}_{2}$ close to that predicted

8 thermodynamically over the whole temperature range.

10 A comparison between Figures $6 \mathrm{a}$ with $\mathrm{b}$ and $\mathrm{c}$ with $\mathrm{d}$ reveals that the proportion of $\mathrm{H}_{2}$ 11 in the gas increases between 300 and $450{ }^{\circ} \mathrm{C}$ when increasing the lactose concentration 12 from 1 to $10 \mathrm{wt} . \%$ and reduces the relative amount of $\mathrm{CO}_{2}$ in the gas for a $\mathrm{W} / \mathrm{m}_{\text {lactose }}$ 13 ratio of $4 \mathrm{~g}$ catalyst $\mathrm{min} / \mathrm{g}$ lactose. These developments account for the formation of $\mathrm{C}$ 14 deposits that lower the amount of $\mathrm{C}$ in the gas as the concentration of lactose increases, 15 thus increasing and decreasing the proportions of $\mathrm{H}_{2}$ and $\mathrm{CO}_{2}$, respectively, especially 16 at low temperatures. An increase in temperature decreases the solid carbon formation 17 allowing thermodynamic composition to be reached for the proportions of $\mathrm{H}_{2}$ and $\mathrm{CO}_{2}$.

19 An increase in the $\mathrm{W} / \mathrm{m}_{\text {lactose }}$ ratio increases the proportion of $\mathrm{H}_{2}$ in the gas and reduces 20 the concentration of $\mathrm{CO}_{2}$ between 300 and $500{ }^{\circ} \mathrm{C}$ for a $1 \mathrm{wt} . \%$ lactose solution. Lactose 21 steam reforming involves an initial thermal decomposition forming $\mathrm{CO}_{2}, \mathrm{CO}$ and other

22 intermediate products that subsequently evolve towards the thermodynamic 23 composition of the gas [32]. At low temperatures, decomposition reactions might 24 prevail over reforming reactions, which results in a gas with a higher and lower 
1 proportion of $\mathrm{H}_{2}$ and $\mathrm{CO}_{2}$, respectively, than those thermodynamically predicted. An

2 increase in the temperature or in the $\mathrm{W} / \mathrm{m}_{\text {lactose }}$ ratio increases the reaction rates of the

3 reforming reactions shifting the proportions of $\mathrm{H}_{2}$ and $\mathrm{CO}_{2}$ towards their

4 thermodynamic value. For a $10 \mathrm{wt} . \%$ lactose solution the $\mathrm{W} / \mathrm{m}_{\text {lactose }}$ ratio exerts a

5 negligible effect on the proportions of $\mathrm{H}_{2}$ and $\mathrm{CO}_{2}$. This is the consequence of the trade-

6 off between the gasification of the carbon deposits (which decreases and increases the

7 proportions of $\mathrm{H}_{2}$ and $\mathrm{CO}_{2}$, respectively) and reforming reactions (which shift the

8 proportion of $\mathrm{H}_{2}$ and $\mathrm{CO}_{2}$ towards their thermodynamic value).

9

a)

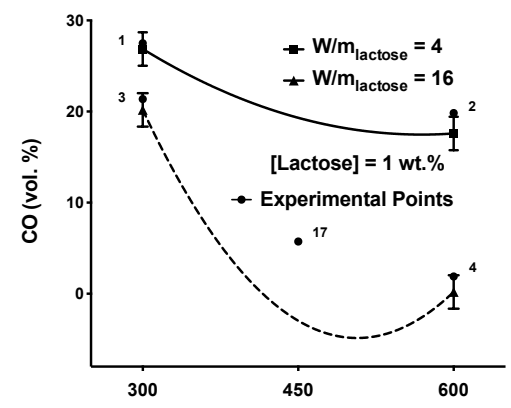

c)

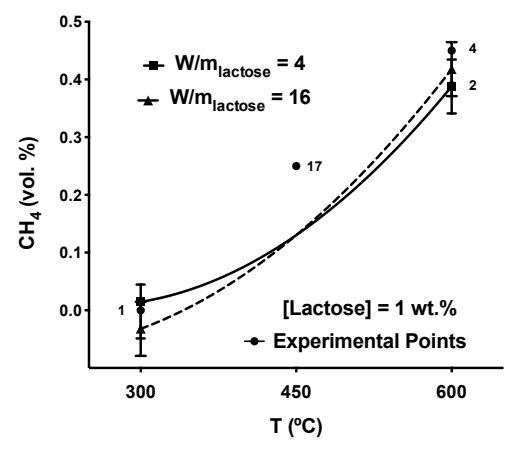

b)

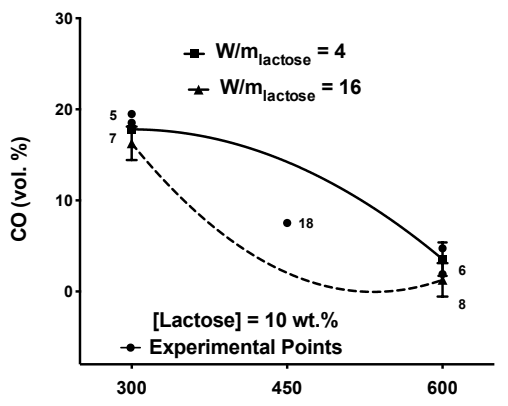

d)

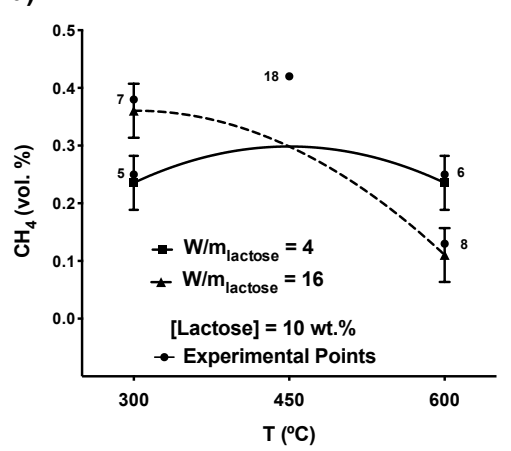

11

Figure 7. Interaction plots for initial relative amounts (vol.\%) of $\mathrm{CO}$ (a and b) and $\mathrm{CH}_{4}$

13 (c and d) in the gas. Bars are LSD intervals with 95\% confidence. 
1 Figure 7 shows how an increase in the temperature decreases the relative amount of $\mathrm{CO}$

2 in the gas. At low temperatures $\left(300-450^{\circ} \mathrm{C}\right)$, lactose is thermally decomposed into a

3 gas with a high proportion of $\mathrm{CO}$ and $\mathrm{CO}_{2}$ [31]. This high proportion of $\mathrm{CO}$ in the gas

4 decreases towards its thermodynamic value when increasing the temperature. In

5 general, an increase in the $\mathrm{W} / \mathrm{m}_{\text {lactose }}$ ratio from 4 to $16 \mathrm{~g}$ catalyst $\mathrm{min} / \mathrm{g}$ lactose

6 decreases the relative amount of $\mathrm{CO}$ in the gas due the greater spread of the water gas

7 shift reaction.

9 The effect of the lactose concentration on the relative amount of $\mathrm{CO}$ in the gas can be 10 observed comparing Figure $7 \mathrm{a}$ with $\mathrm{b}$. An increase in the lactose concentration for a

$11 \mathrm{~W} / \mathrm{m}_{\text {lactose }}$ ratio of $4 \mathrm{~g}$ catalyst $\mathrm{min} / \mathrm{g}$ lactose decreases the proportion of $\mathrm{CO}$ in the gas, 12 especially at temperatures higher than $450{ }^{\circ} \mathrm{C}$ due to the low amount of $\mathrm{C}$ of the gas 13 phase. Conversely, for a $\mathrm{W} / \mathrm{m}_{\text {lactose }}$ ratio of $16 \mathrm{~g}$ catalyst $\mathrm{min} / \mathrm{g}$ lactose the effect of the 14 concentration of lactose is not significant. At temperatures higher than $450{ }^{\circ} \mathrm{C}$, the 15 reforming process is favoured and a thermodynamic concentration for the $\mathrm{CO}$ is 16 obtained. At temperatures lower than $450{ }^{\circ} \mathrm{C}$ there is a trade-off between the 17 gasification of carbon deposits and the higher extension of the WGS reaction.

19 The proportion of $\mathrm{CH}_{4}$ in the gas is lower than 0.5 vol.\% in all cases. For a $1 \mathrm{wt} . \%$ 20 lactose solution the concentration of $\mathrm{CH}_{4}$ increases with temperature regardless of the $21 \mathrm{~W} / \mathrm{m}_{\text {lactose }}$ ratio. The proportion of $\mathrm{C}$ in the gas increases with temperature, which can 22 increase the concentration of $\mathrm{CH}_{4}$. For a $10 \mathrm{wt} . \%$ lactose solution and employing $4 \mathrm{~g}$ 23 catalyst $\mathrm{min} / \mathrm{g}$ lactose, the temperature does not have a significant influence, while for a $2416 \mathrm{~g}$ catalyst $\mathrm{min} / \mathrm{g}$ lactose the relative amount of $\mathrm{CH}_{4}$ drops as the temperature 
1 increases. At temperatures higher than $450{ }^{\circ} \mathrm{C}$ the evaporation of the feed and the

2 reforming process are favoured but the thermodynamic proportion of $\mathrm{CH}_{4}$ decreases. A

3 comparison between Figure $7 \mathrm{c}$ and d shows how an increase in the concentration of

4 lactose increases the proportion of $\mathrm{CH}_{4}$ in the gas between 300 and $500{ }^{\circ} \mathrm{C}$ due to the

5 thermodynamics. Between 450 and $600{ }^{\circ} \mathrm{C}$ the same increase in the concentration of

6 lactose causes a decrease in the concentration of $\mathrm{CH}_{4}$ in the gas.

7

8 3.2.3 Liquid composition

9 The liquid phase is made up of a mixture of aldehydes (acetaldehyde and propanal),

10 ketones (2-propanone), carboxylic acids (acetic and propionic acids), sugars

11 (levoglucosan and D-alose), furans (furfural, 2-furancarboxaldehyde and 2,5-

12 furandicarboxaldehyde), alcohols (ethanol, propanol and cyclic alcohols) and phenolic

13 compounds (phenol and methyl-phenols). The presence of these compounds in the

14 liquid phase, which is consistent with the reaction pathway proposed in Figure 1, is the

15 result of the thermal decomposition of lactose and the incomplete reforming of lactose

16 and its liquid intermediates. All these reaction intermediates have a high tendency to

17 form coke (especially sugars, furans and aromatic species) [36, 52-55] which explains

18 the formation of coke observed experimentally and the high proportion of $\mathrm{CO}$ and $\mathrm{CO}_{2}$

19 in the gas under some experimental conditions.

21 Figure 8 plots the relative amounts of each of the different families of liquid compounds

22 for the different experiments represented in 3 intervals of 60 minutes, together with the

23 results of the Fischer's LSD test. The results from the statistical analysis (ANOVA)

24 revealed significant differences in the concentrations of aldehydes, ketones, carboxylic 
1 acids, sugars, furans, alcohols and phenols ( $\mathrm{p}$-values $<0.05$ ). The proportion of these

2 compounds in the liquid, expressed as relative chromatographic area, is as follows.

3 Aldehydes: 0-100 \%, ketones: 0-99\%, carboxylic acids: 0-29\%, furans: 0-99\%, sugars:

$4 \quad 0-89 \%$, alcohols: $0-9 \%$ and phenols: $0-4 \%$. For the operating conditions where a

5 negligible formation of liquid is achieved (high temperature and $\mathrm{W} / \mathrm{m}_{\text {lactose }}$ ratio), the

6 liquid phase is made up of aldehydes and of a mixture of ketones and sugars when

7 feeding a 1 and a 10 wt.\% lactose solution, respectively.

8 

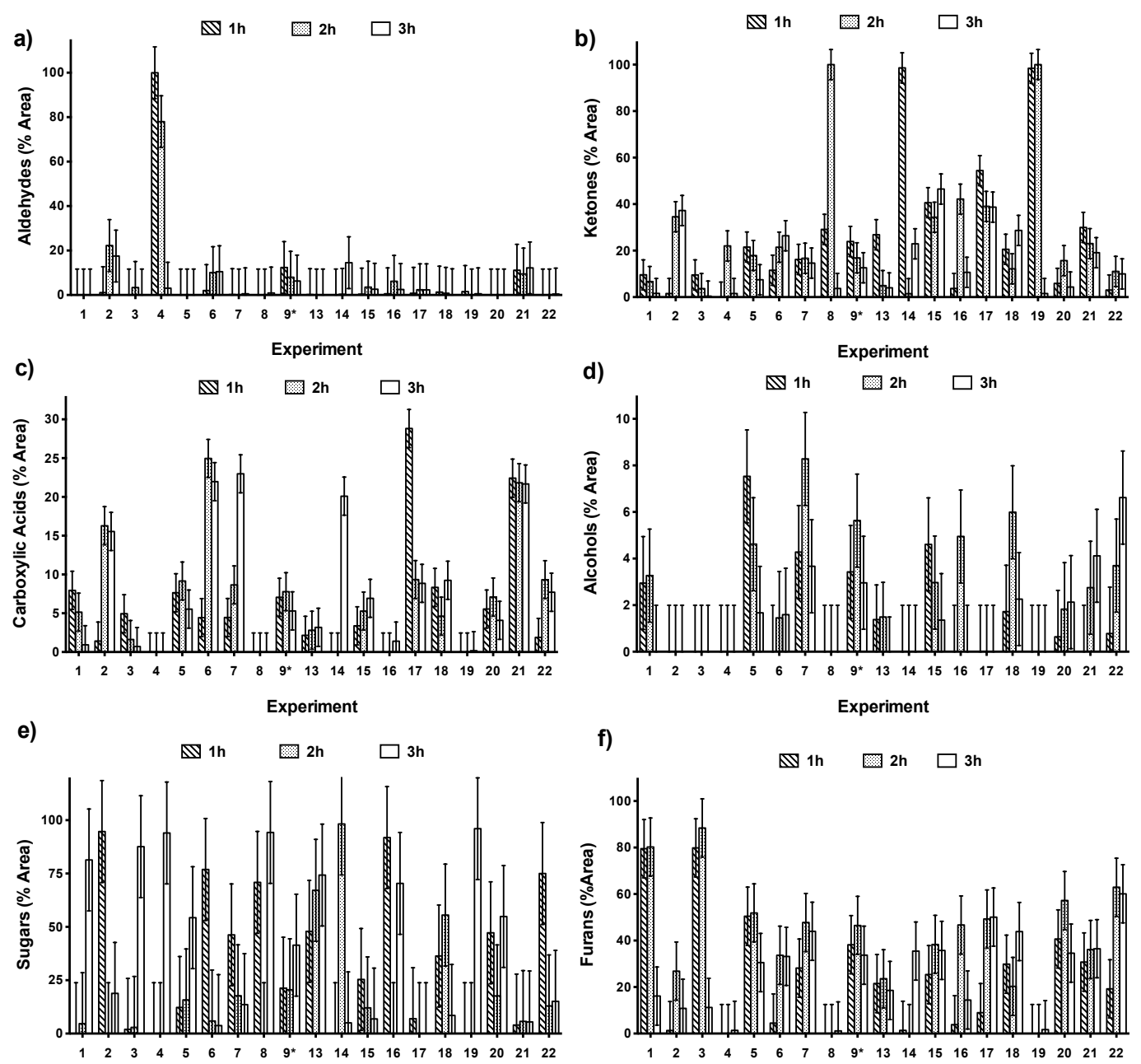

f)
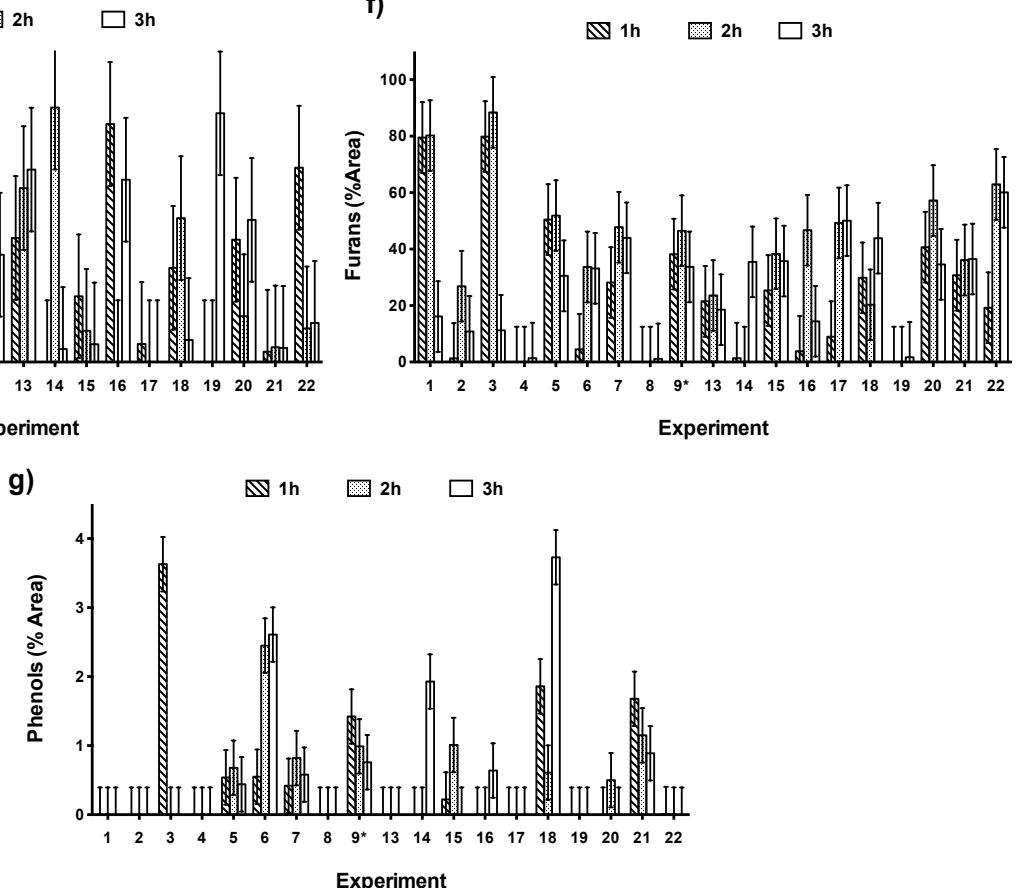

2 Figure 8. Liquid composition results are presented as the relative chromatographic

3 area divided into three intervals of $1 \mathrm{~h}$ for the different families of compounds and

4 expressed as mean \pm 0.5 Fisher LSD intervals with 95\% confidence. 
1 Studying the evolution over time for these compounds, two tendencies are found.

2 Aldehydes, alcohols and phenols remain relatively steady, while high variations over

3 time can be seen for ketones, carboxylic acids, sugars and furans. Aldehydes display a

4 decrease in their relative area in run 4 . The relative amount of phenols decreases for run

53 and increases for runs 6,14 and 18. Increases in the proportion of ketones are found

6 for runs 2 and 6 while decreases take place for runs 5, 8, 13, 14, 17 and 19. Carboxylic

7 acids display increases for runs 2, 6, 7, 14 and 22 and decreases for runs 1 and 17. The

8 proportion of sugars increases for runs 1, 3, 4 and 19 and decreases for runs 2, 6 and 22.

9 The relative amount of furans in the liquid increases for runs 6, 14, 17 and 22 and

10 decreases for runs 1 and 3.

12 To gain a better insight into the variations over time of these compounds, a multivariate 13 analysis by means of Spearman's test was conducted to find significant relationships 14 between the proportions of these compounds in the liquid phase. This test reveals 15 significant relationships with $95 \%$ confidence between the proportions of furans and 16 carboxylic acids ( $\mathrm{p}$-value $\left.=0.0001 ; \mathrm{R}^{2}=0.65\right)$; carboxylic acids and ketones ( $\mathrm{p}$-value $=$

$\left.170.0001 ; \mathrm{R}^{2}=0.35\right)$; carboxylic acids and sugars $\left(\mathrm{p}\right.$-value $\left.=0.0001 ; \mathrm{R}^{2}=0.65\right)$; furans 18 and alcohols ( $\mathrm{p}$-value $\left.=0.0001 ; \mathrm{R}^{2}=0.63\right)$; furans and sugars $\left(\mathrm{p}\right.$-value $=0.0001 ; \mathrm{R}^{2}=$ 19 0.36); alcohols and phenols ( $\mathrm{p}$-value $\left.=0.0001 ; \mathrm{R}^{2}=0.46\right)$ and phenols and carboxylic 20 acids $\left(\mathrm{p}\right.$-value $\left.=0.0001 ; \mathrm{R}^{2}=0.56\right)$. These relationships account for the experimental 21 observations and the reaction pathway shown in Figure 1. The test reveals that the 22 increase in the proportion of sugars takes place together with decreases in the 23 proportions of furans and ketones. 
1 The specific effects of the operating conditions as well as their possible interactions on

2 the liquid composition were studied considering the results obtained during the first 60

3 minutes of reaction. Table 8 shows the significant terms in the codec model and their

4 relative influence in the process according to the cause-effect Pareto test and the

5 ANOVA analysis for the different families of compounds. Sugars, furans, aldehydes,

6 ketones and carboxylic acids are the compounds displaying the highest variations in

7 their proportions during the first hour of experiment, and consequently they are the most

8 influenced by the operating conditions. Thus, only the influence of the operating

9 conditions on the proportion of these families has been discussed in depth.

11 Table 8. Relative influence of the operating conditions on the liquid composition

12 according to the ANOVA analysis for the first hour of reaction.

13

\begin{tabular}{|c|c|c|c|c|c|c|c|c|c|c|c|c|c|c|c|c|c|c|}
\hline Variable & $\mathbf{R}^{2}$ & I. Term & $\mathbf{T}$ & $\mathbf{W}$ & C & TW & TC & WC & TWC & $T^{2}$ & $\mathbf{W}^{2}$ & $\mathrm{C}^{2}$ & $T^{2} W$ & $\mathbf{T}^{2} \mathbf{C}$ & $T^{T} W^{2}$ & $T^{2}$ & $\mathbf{W C}^{2}$ & TWC $^{2}$ \\
\hline $\begin{array}{l}\text { Ketones } \\
(\%)\end{array}$ & 0.98 & 39.11 & $\begin{array}{l}31.87 \\
(13)\end{array}$ & $\begin{array}{l}-18.45 \\
\text { (3) }\end{array}$ & $\begin{array}{l}-16.92 \\
(2)\end{array}$ & $\begin{array}{l}16.4 \\
(7)\end{array}$ & ns & ns & ns & $\begin{array}{l}16.42 \\
(1)\end{array}$ & $\begin{array}{l}-24.13 \\
(13)\end{array}$ & $\begin{array}{l}-8.82 \\
(9)\end{array}$ & $\begin{array}{l}36.27 \\
(9)\end{array}$ & $\begin{array}{l}24.14 \\
(9)\end{array}$ & $\mathrm{ns}$ & $\begin{array}{l}-33.7 \\
(18)\end{array}$ & $\begin{array}{l}-16.48 \\
(8)\end{array}$ & $\begin{array}{l}-13.72 \\
(6)\end{array}$ \\
\hline $\begin{array}{l}\text { C. Acids } \\
\text { (\%) }\end{array}$ & 0.99 & 13.26 & ns & $\begin{array}{l}-1.69 \\
(10)\end{array}$ & $\begin{array}{l}-10.25 \\
(7)\end{array}$ & $\begin{array}{l}-6.52 \\
(9)\end{array}$ & ns & ns & ns & $\begin{array}{l}-7.68 \\
(7)\end{array}$ & $\begin{array}{l}-7.07 \\
(10)\end{array}$ & $\begin{array}{l}9.81 \\
(7)\end{array}$ & $\begin{array}{l}-3 \\
(4)\end{array}$ & $\begin{array}{l}10.52 \\
(15)\end{array}$ & $\begin{array}{l}3.75 \\
(1)\end{array}$ & $\begin{array}{l}-6.14 \\
(11)\end{array}$ & $\begin{array}{l}3.18 \\
(5)\end{array}$ & $\begin{array}{l}6.56 \\
(12)\end{array}$ \\
\hline $\begin{array}{l}\text { Furans } \\
(\%)\end{array}$ & 0.99 & 24.44 & $\begin{array}{l}-8.22 \\
(28)\end{array}$ & $\begin{array}{l}-10.78 \\
(6)\end{array}$ & $\begin{array}{l}10.43 \\
(7)\end{array}$ & $\begin{array}{l}-13.1 \\
(4)\end{array}$ & $\begin{array}{l}10.5 \\
(11)\end{array}$ & $\begin{array}{l}-3.24 \\
(3)\end{array}$ & ns & $\begin{array}{l}-9.06 \\
(2)\end{array}$ & $\begin{array}{l}-5.91 \\
(0.5)\end{array}$ & ns & $\begin{array}{l}7.69 \\
(4)\end{array}$ & $\begin{array}{l}-20.12 \\
(9)\end{array}$ & ns & $\begin{array}{l}-20.81 \\
(14)\end{array}$ & ns & $\begin{array}{l}15.07 \\
(9)\end{array}$ \\
\hline $\begin{array}{l}\text { Sugars } \\
(\%)\end{array}$ & 0.99 & 7.81 & $\begin{array}{l}-23.94 \\
(1)\end{array}$ & $\begin{array}{l}33.26 \\
(2)\end{array}$ & $\begin{array}{l}13.9 \\
(11)\end{array}$ & $\begin{array}{l}5.94 \\
(8)\end{array}$ & ns & $\begin{array}{l}15.07 \\
(11)\end{array}$ & $\begin{array}{l}7.07 \\
(5)\end{array}$ & Ns & $\begin{array}{l}35.45 \\
(10)\end{array}$ & $\begin{array}{l}-1.53 \\
(2)\end{array}$ & $\begin{array}{l}- \\
41.31 \\
(14)\end{array}$ & ns & $\begin{array}{l}-5.61 \\
(2)\end{array}$ & $\begin{array}{l}52.29 \\
(24)\end{array}$ & ns & $\begin{array}{l}-23.03 \\
(10)\end{array}$ \\
\hline $\begin{array}{l}\text { Aldehydes } \\
(\%)\end{array}$ & 0.99 & -0.64 & ns & ns & ns & $\begin{array}{l}-2.39 \\
(9)\end{array}$ & $\begin{array}{l}-12.4 \\
(11)\end{array}$ & $\begin{array}{l}-12.6 \\
(11)\end{array}$ & $\begin{array}{l}-12.64 \\
(11)\end{array}$ & $\begin{array}{l}2.74 \\
(4)\end{array}$ & $\begin{array}{l}3.11 \\
(2)\end{array}$ & $\begin{array}{l}3.69 \\
(7)\end{array}$ & $\begin{array}{l}-2.38 \\
(2)\end{array}$ & $\begin{array}{l}-12.36 \\
(11)\end{array}$ & $\begin{array}{l}3.18 \\
(2)\end{array}$ & $\begin{array}{l}9.68 \\
(12)\end{array}$ & $\begin{array}{l}14.52 \\
(11)\end{array}$ & $\begin{array}{l}14.48 \\
(8)\end{array}$ \\
\hline $\begin{array}{l}\text { Alcohols } \\
(\%)\end{array}$ & 0.90 & 2.66 & ns & $\begin{array}{l}-2.3 \\
(13)\end{array}$ & $\begin{array}{l}1.06 \\
(15)\end{array}$ & ns & $\begin{array}{l}-1.11 \\
(14)\end{array}$ & ns & ns & $\begin{array}{l}-1.29 \\
(12)\end{array}$ & ns & $\begin{array}{l}-1.12 \\
\text { (3) }\end{array}$ & $\begin{array}{l}1.78 \\
(10)\end{array}$ & ns & ns & $\begin{array}{l}-1.84 \\
(23)\end{array}$ & ns & $\begin{array}{l}0.77 \\
(10)\end{array}$ \\
\hline $\begin{array}{l}\text { Phenols } \\
\text { (\%) }\end{array}$ & 0.98 & 1.32 & ns & ns & $\begin{array}{l}0.93 \\
(1)\end{array}$ & $\begin{array}{l}-0.48 \\
(13)\end{array}$ & $\begin{array}{l}0.4 \\
(9)\end{array}$ & $\begin{array}{l}-0.54 \\
(12)\end{array}$ & $\begin{array}{l}0.4 \\
(9)\end{array}$ & $\begin{array}{l}-0.61 \\
(9)\end{array}$ & $\begin{array}{l}-0.5 \\
(3)\end{array}$ & ns & $\begin{array}{l}-0.42 \\
(3)\end{array}$ & $\begin{array}{l}-1.19 \\
(12)\end{array}$ & $\begin{array}{l}0.42 \\
(6)\end{array}$ & $\begin{array}{l}-0.92 \\
(12)\end{array}$ & $\begin{array}{l}0.79 \\
(10)\end{array}$ & ns \\
\hline
\end{tabular}

14 ns. Non significant with $95 \%$ confidence

16 Response variable $=$ Independent term + Coefficient $\mathrm{T} \cdot \mathrm{T}+$ Coefficient $\mathrm{W} \cdot \mathrm{W}+$ Coefficient $\mathrm{C} \cdot \mathrm{C}+\mathrm{Coefficient} \mathrm{TW} \cdot \mathrm{TW}+\mathrm{Coefficient}$

17 TC $\cdot \mathrm{TC}+$ Coefficient $\mathrm{WC} \cdot \mathrm{WC}+$ Coefficient $\mathrm{TWC} \cdot \mathrm{TWC}+$ Coefficient $\mathrm{T}^{2} \cdot \mathrm{T}^{2}+$ Coefficient $\mathrm{W}^{2} \cdot \mathrm{W}^{2}+\mathrm{Coefficient}^{2} \cdot \mathrm{C}^{2}+\mathrm{Coefficient}$

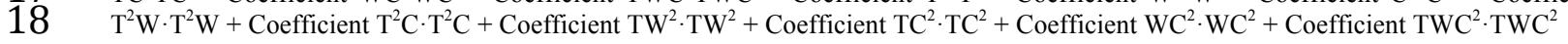

21 The relative influence of the operating conditions on the liquid composition summarised

22 in Table 8 indicates that the temperature and the $\mathrm{W} / \mathrm{m}_{\text {lactose }}$ exert the greatest influence

23 on the proportion of these liquids. Lactose decomposition is a competitive process

24 involving competition between fragmentation and polymeric reactions. Therefore the

25 operating conditions significantly influence the composition of the liquid phase [56]. 
a)

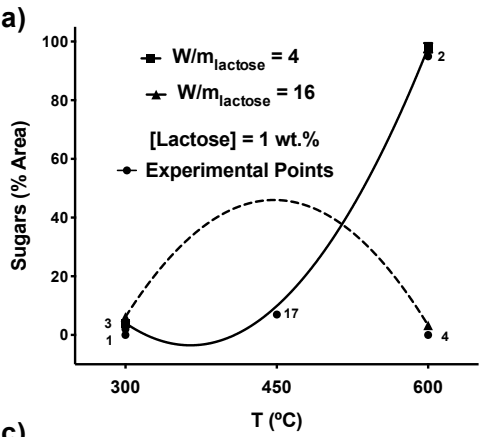

c)

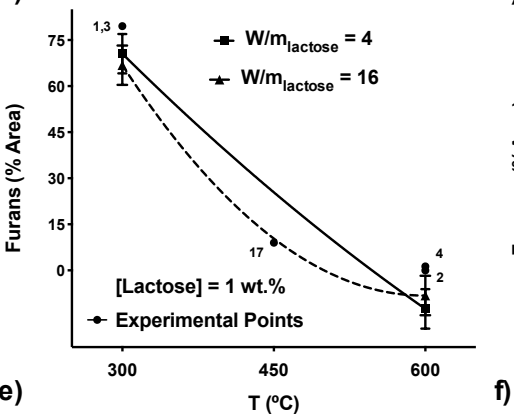

e)

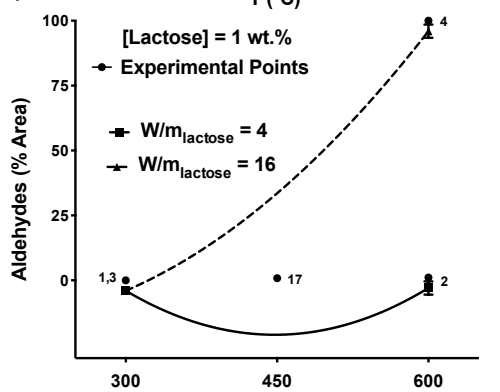

g)
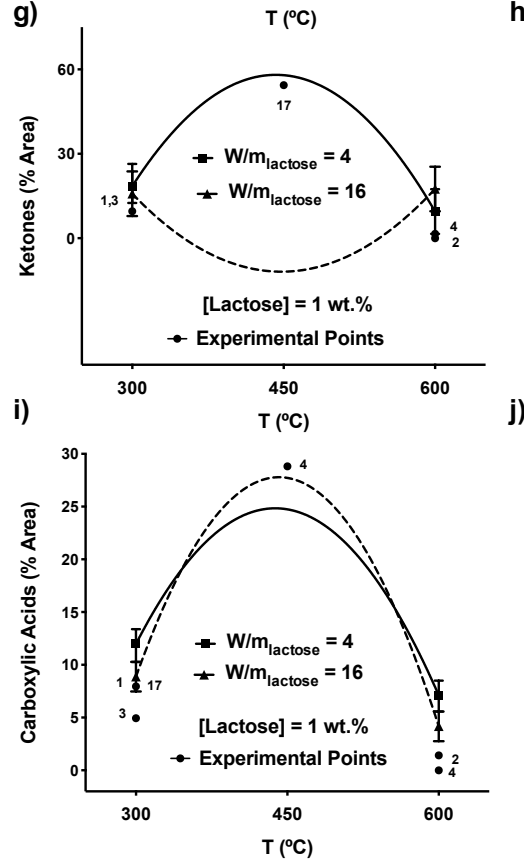

b)

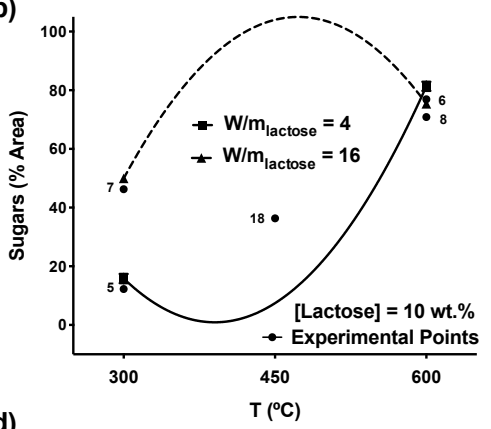

d)
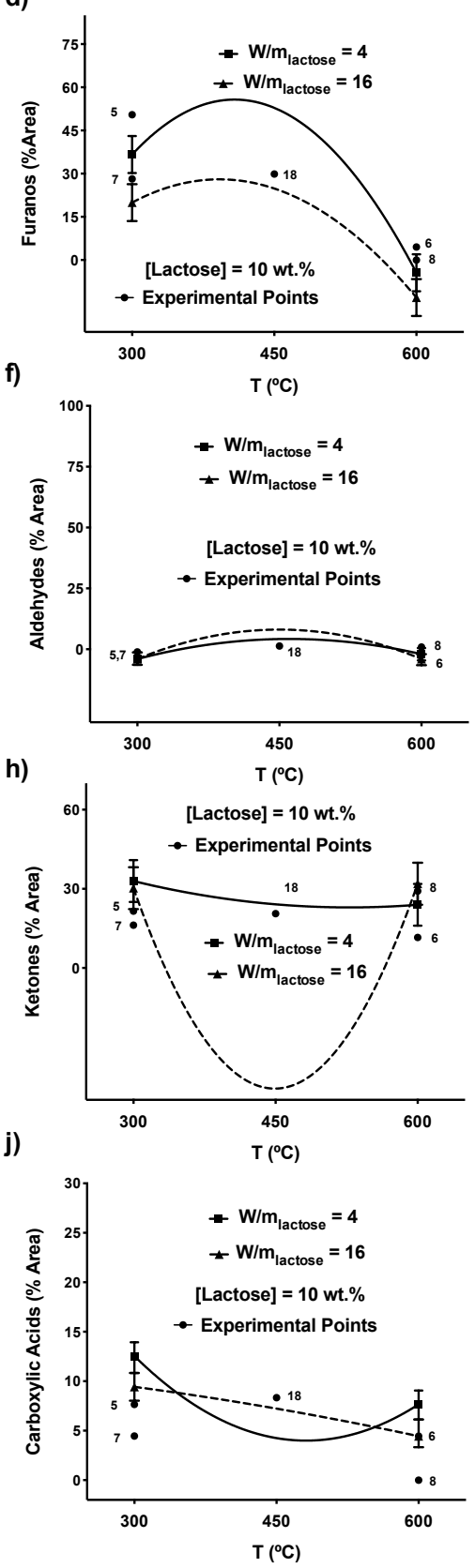

Figure 9. Interaction plots for initial relative amounts (vol.\%) of sugars (a and b),

3 furans ( $c$ and $d$ ), aldehydes (e and $f$ ), ketones ( $g$ and $h$ ) and carboxylic acids ( $i$ and $j$ ).

4 Bars are LSD intervals with 95\% confidence. 
2 The temperature, residence time and $\mathrm{pH}$ are the most influential parameters affecting

3 product distribution during the thermal decomposition of carbohydrates [57]. Figure 9

4 summarises the effect of the operating variables and the most important interactions on

5 the liquid product distribution according to the ANOVA analysis. The evolution of

6 these variables was obtained from the ANOVA analysis (Table 8) of all the experiments

7 performed (Table 4). In addition, when possible, some experimental points were added.

8 Some plots predict slightly negative relative areas due to the experimental character of

9 the models. Specifically, Figures 9 a, c, e, g and i show the effect of the temperature on

10 the proportion of sugars, furans, aldehydes, ketones and carboxylic acids in the liquids

11 for $\mathrm{W} / \mathrm{m}_{\text {lactose }}$ ratios of 4 and $16 \mathrm{~g}$ catalyst $\mathrm{min} / \mathrm{g}$ lactose when a $1 \mathrm{wt} . \%$ lactose solution

12 was used. These effects are plotted for a $10 \mathrm{wt} . \%$ lactose solution in Figures $9 \mathrm{~b}, \mathrm{~d}, \mathrm{f}, \mathrm{h}$ 13 and $\mathrm{j}$.

\section{$15 \quad$ 3.2.3.1 Sugars}

16 The influence of the temperature on the proportion of sugars in the liquid depends on

17 the $\mathrm{W} / \mathrm{m}_{\text {lactose }}$ ratio. For $4 \mathrm{~g}$ catalyst $\mathrm{min} / \mathrm{g}$ lactose the temperature does not exert a

18 significant effect between 300 and $400{ }^{\circ} \mathrm{C}$, where a liquid free of sugars is obtained. An

19 increase in the temperature between 400 and $600{ }^{\circ} \mathrm{C}$ dramatically increases the

20 proportion of sugars as their formation is favoured at high temperatures [40].

21 Conversely, for a $\mathrm{W} / \mathrm{m}_{\text {lactose }}$ ratio of $16 \mathrm{~g}$ catalyst $\mathrm{min} / \mathrm{g}$ lactose, a rise in the proportion

22 of sugars takes place as the temperature increases from 300 to $450{ }^{\circ} \mathrm{C}$. A posterior drop

23 follows this increase when the temperature is further increased up to $600{ }^{\circ} \mathrm{C}$. The

24 increase in the $\mathrm{W} / \mathrm{m}_{\text {lactose }}$ ratio promotes the transformation of sugars into gases, thus

25 reducing their proportion in the liquid phase. 
2 The $\mathrm{W} / \mathrm{m}_{\text {lactose }}$ ratio exerts a significant influence on the proportion of sugars. Between

3300 and $450{ }^{\circ} \mathrm{C}$ an increase in this ratio leads to an increase in the proportion of sugars

4 in the liquid. Within this temperature range, an increment in the amount of catalyst

5 helps to decrease the formation of carbon deposits, which increases the formation of

6 liquid products. However, at temperatures of $450{ }^{\circ} \mathrm{C}$ and beyond, where the reforming

7 process is more favoured, this same increase leads to a decrease in the proportion of

8 sugars for a $1 \mathrm{wt} . \%$ solution, probably due to their steam reforming to produce gases.

9 This effect is not observed for a $10 \mathrm{wt} . \%$ solution, since the formation of sugars is more

10 favoured when increasing the concentration of lactose in the feed.

12 The effect of the lactose concentration on the proportion of sugars in the liquid depends

13 on the $\mathrm{W} / \mathrm{m}_{\text {lactose }}$ ratio. For $4 \mathrm{~g}$ catalyst $\mathrm{min} / \mathrm{g}$ lactose, the effect of the concentration is

14 relatively small, while for $16 \mathrm{~g}$ catalyst $\mathrm{min} / \mathrm{g}$ lactose an increase in the concentration of

15 lactose in the feed greatly increases the relative amount of sugars in the liquid. A lower

16 amount of water can help to shift the dehydration reactions of glucose and galactose

17 towards the production sugars.

\subsubsection{Furans}

20 The highest proportion of furans in the liquid occurs at low temperatures, where their

21 formation might be favoured. An increase in the temperature decreases their proportion

22 in the liquid due to the greater extension of reforming reactions to produce gases. The

23 effect of the $\mathrm{W} / \mathrm{m}_{\text {lactose }}$ ratio is only significant for a concentrated lactose solution (10

24 wt.\%). Under these conditions, an increase in the amount of catalyst reduces the relative 
1 amount of furans in the liquid between 300 and $450{ }^{\circ} \mathrm{C}$. Within this temperature range,

2 an increase in the $\mathrm{W} / \mathrm{m}_{\text {lactose }}$ ratio increases the $\mathrm{CC}$ gas, which increases the proportion

3 of sugars, thus reducing the relative amount of furans in the liquid. Moreover, an

4 increase in the $\mathrm{W} / \mathrm{m}_{\text {lactose }}$ ratio also aids the transformation of furans into phenolic

5 compounds and gases, which accounts for the drop observed for this family and is in

6 agreement with the reaction pathway proposed in Figure 1. The lactose concentration is

7 only significant at temperatures between 300 and $400{ }^{\circ} \mathrm{C}$, where an increase from 1 to

$8 \quad 10 \mathrm{wt} . \%$ reduces the proportion of furans in the liquid. The increase observed in the

9 proportion of sugars due to the lower excess of water accounts for this variation.

\section{$11 \quad 3.2 .3 .3$ Aldehydes}

12 The influence of the temperature on the proportion of aldehydes in the liquid depends

13 on the concentration of lactose and the $\mathrm{W} / \mathrm{m}_{\text {lactose }}$ ratio. For a $1 \mathrm{wt} . \%$ lactose solution

14 employing a $\mathrm{W} / \mathrm{m}_{\text {lactose }}$ ratio of $4 \mathrm{~g}$ catalyst $\mathrm{min} / \mathrm{g}$ lactose, the temperature does not exert

15 a significant effect on the proportion of aldehdydes in the liquid. For a ratio of $16 \mathrm{~g}$

16 catalyst $\mathrm{min} / \mathrm{g}$ lactose, an increase in temperature increases the proportion of aldehydes.

17 Acetalydehyde, obtained from the fragmentation of glucose and galactose, is the major

18 constituent of this family. High temperatures favours linear aldehyde production [56],

19 which is in agreement with the experimental results of this work. For a $10 \mathrm{wt} . \%$ solution

20 the effect of the temperature and $\mathrm{W} / \mathrm{m}_{\text {lactose }}$ on the proportion of aldehydes is weak, and

21 a proportion of aldehydes lower than 5\% is obtained within the whole temperature range

22 considered in this work. 
2 The effect of the temperature on this family depends on the other two operating

3 variables. When a $1 \mathrm{wt} . \%$ lactose solution and a $\mathrm{W} / \mathrm{m}_{\text {lactose }}$ ratio of $4 \mathrm{~g}$ catalyst $\mathrm{min} / \mathrm{g}$

4 lactose are used, an increase in the temperature initially increases the proportion of

5 ketones from 300 to $450{ }^{\circ} \mathrm{C}$, while a further increase up to $600{ }^{\circ} \mathrm{C}$ reduces their relative

6 amount. For a $\mathrm{W} / \mathrm{m}_{\text {lactose }}$ ratio of $16 \mathrm{~g}$ catalyst $\mathrm{min} / \mathrm{g}$ lactose, the opposite trend with the

7 temperature is observed. Low temperatures can favour the extension of retroaldolic

8 reactions, increasing the proportion of ketones in the liquid. An increase in temperature

9 might favour their transformation into other liquid intermediates and/or gases. For $16 \mathrm{~g}$

10 catalyst $\mathrm{min} / \mathrm{g}$ lactose, the initial decrease in the proportion of ketones takes place

11 together with an increase in the relative amounts of aldehydes and sugars, which might

12 indicate a lower reactivity of ketones in steam reforming [36, 58, 59].

14 For a $10 \mathrm{wt}$ \% lactose solution the temperature does not exert a significant influence for

$15 \mathrm{a} \mathrm{W} / \mathrm{m}_{\text {lactose }}$ ratio of $4 \mathrm{~g}$ catalyst $\mathrm{min} / \mathrm{g}$ lactose. However, an initial decrease in the

16 proportion of ketones takes place for temperatures from 300 to $450{ }^{\circ} \mathrm{C}$ followed by a

17 posterior increase from 450 to $600{ }^{\circ} \mathrm{C}$ when a $\mathrm{W} / \mathrm{m}_{\text {lactose }}$ ratio of $16 \mathrm{~g}$ catalyst $\mathrm{min} / \mathrm{g}$

18 lactose is used. The higher formation of carbon deposits when feeding a concentrated

19 lactose solution, which decreases the fraction of vaporised organic compounds, might

20 hinder any increase in ketones with the temperature; thus the ketones follow the same

21 trend as found for a $1 \mathrm{wt} . \%$ lactose solution. As the temperature increases and the CC

22 sol decreases, the proportion of ketones reaches the same value as that for a $1 \mathrm{wt} . \%$

23 solution. 
1 The effect of the concentration of lactose is found to be significant only between 400

2 and $500{ }^{\circ} \mathrm{C}$ for a $\mathrm{W} / \mathrm{m}_{\text {lactose }}$ ratio of $4 \mathrm{~g}$ catalyst $\mathrm{min} / \mathrm{g}$ lactose. Under these conditions an

3 increase in the concentration of lactose decreases the relative amount of ketones in the

4 liquid. Retroaldolic reactions might be favoured when high $\mathrm{S} / \mathrm{C}$ and low $\mathrm{W} / \mathrm{m}_{\text {lactose }}$ ratios

5 are used. A greater amount of catalyst might increase the reaction rates of the reforming

6 reactions, thus increasing gas production.

7

\section{$8 \quad$ 3.2.3.5 Carboxylic acids}

9 Carboxylic acids are intermediate products in lactose steam reforming. They are

10 obtained at low temperatures from the decomposition of glucose and galactose by

11 fragmentation and retroaldol reactions [40]. They can be obtained from alcohol

12 dehydration and aldehyde oxidation. The effect of the temperature depends on the

13 concentration of lactose. For a $1 \mathrm{wt} . \%$ solution, an increase in their relative amount

14 takes place between 300 and $450{ }^{\circ} \mathrm{C}$ regardless of the $\mathrm{W} / \mathrm{m}_{\text {lactose }}$ ratio, reaching a

15 maximum in the proportion of carboxylic acids at $450^{\circ} \mathrm{C}$. Lactose decomposition

16 through retroaldol and fragementation reactions might be favoured at this temperature

17 range. A further increase in the temperature up to $600{ }^{\circ} \mathrm{C}$ reduces the proportion of

18 carboxylic acids, probably due to their transformation into other liquid products and/or

19 gases. For a 10 wt.\% lactose solution a mild decrease with temperature takes places.

20 The $\mathrm{W} / \mathrm{m}_{\text {lactose }}$ ratio does not significantly influence the proportion of carboxylic acids,

21 while the concentration of lactose exerts a significant influence decreasing the

22 proportion of acids in the condensate as the lactose concentration increases from 1 to 10

23 wt. \%. 
2 Optimal conditions for hydrogen production were sought making use of the

3 experimental models developed for the optimisation and scaling-up of this valorisation

4 process. The predicted $\mathrm{R}^{2}$ of all the models is higher than 0.90 , allowing their use for

5 prediction purposes. Three different optimisations were carried out. The first was the

6 optimisation of the temperature for processing the highest amount of lactose, i.e.

7 maximising the concentration of lactose in the feed. The second and the third aimed at

8 optimising the process for the treatment of real cheese whey, fixing the concentration of

9 lactose at 5.5 wt.\% (the usual concentration of lactose in cheese whey) and maximising

10 the $\mathrm{CC}$ gas and the proportion of $\mathrm{H}_{2}$ in the gas. In the second optimisation the

11 temperature and the $\mathrm{W} / \mathrm{m}_{\text {lactose }}$ ratio were minimised, while no restrictions for these two

12 variables were considered in the third optimisation. Additionally, the evolution over

13 time of the $\mathrm{CC}$ gas and the proportion of $\mathrm{H}_{2}$ in the gas were minimised in all the

14 optimisations.

16 Table 9. Theoretical optimisation: Objectives, optimum values for the operating

17 variables and optimised values for some responses

\begin{tabular}{|c|c|c|c|c|c|c|c|c|c|}
\hline \multirow[t]{2}{*}{ Variable } & \multicolumn{3}{|c|}{ Optimisation 1} & \multicolumn{3}{|c|}{ Optimisation 2} & \multicolumn{3}{|c|}{ Optimisation 3} \\
\hline & Objective & Importance & Optimum & Objective & Importance & Optimum & Objective & Importance & Optimum \\
\hline $\mathrm{T}\left({ }^{\circ} \mathrm{C}\right)$ & Minimum & 1 & 559 & Minimum & 2 & 506 & None & 2 & 586 \\
\hline$[$ Lactose] (wt.\%) & Maximum & 2 & 10 & Fixed & 2 & 5.5 & Fixed & 2 & 5.5 \\
\hline $\mathrm{W} / \mathrm{m}_{\text {lactose }}$ (g cat $\mathrm{min} / \mathrm{g}$ lactose) & None & 2 & 16 & Minimum & 1 & 15 & None & 1 & 16 \\
\hline $\mathrm{CC}$ gas $(\%)$ & Maximum & 5 & 78 & Maximum & 5 & 72 & Maximum & 5 & 88 \\
\hline CC liq (\%) & Minimum & 3 & 2.5 & Minimum & 3 & 6 & Minimum & 3 & 0 \\
\hline CC sol (\%) & Minimum & 5 & 14 & Minimum & 5 & 18 & Minimum & 5 & 12 \\
\hline $\mathrm{H}_{2}(\operatorname{vol} . \%)$ & Maximum & 4 & 65 & Maximum & 4 & 66 & Maximum & 4 & 67 \\
\hline $\mathrm{CO}_{2}(\mathrm{vol} . \%)$ & None & 3 & 33 & None & 3 & 31 & None & 3 & 29 \\
\hline CO (vol.\%) & None & 3 & 0.2 & None & 3 & 0 & None & 3 & 0.7 \\
\hline $\mathrm{CH}_{4}(\mathrm{vol} . \%)$ & None & 3 & 0.2 & None & 3 & 0.2 & None & 3 & 0.2 \\
\hline Var CC gas (\%) & Minimum & 2 & 13 & Minimum & 2 & 26 & Minimum & 2 & 8 \\
\hline Var vol. $\mathrm{H}_{2}(\%)$ & Minimum & 2 & -5 & Minimum & 2 & -6 & Minimum & 2 & -2 \\
\hline
\end{tabular}


1 To meet these objectives, a solution that strikes a compromise between the optimum

2 values for all the response variables was sought. To do so, a relative importance (from 1

3 to 5) was given to each of the objectives in order to come up with the solution that

4 satisfies all the criteria. Table 9 lists the relative importance assigned to each variable,

5 the criteria used in the optimisations and the optimisation results.

7 A possible optimum for maximising the concentration of lactose in the feed was found 8 at $559^{\circ} \mathrm{C}$ employing a $\mathrm{W} / \mathrm{m}_{\text {lactose }}$ ratio of $16 \mathrm{~g}$ catalyst $\mathrm{min} / \mathrm{g}$ lactose (Opt. 1). These

9 conditions provide a CC gas of $78 \%$ with a proportion of $\mathrm{H}_{2}$ in the gas of $65 \mathrm{vol} . \%$.

10 When feeding a lactose concentration of 5.5\%, an optimum for $\mathrm{H}_{2}$ production takes 11 place at $506^{\circ} \mathrm{C}$ using a $\mathrm{W} / \mathrm{m}_{\text {lactose }}$ ratio of $15 \mathrm{~g}$ catalyst $\mathrm{min} / \mathrm{g}$ lactose (Opt. 2). These

12 conditions provide a $\mathrm{CC}$ gas of $72 \%$ with a relative amount of $\mathrm{H}_{2}$ in the gas of $66 \mathrm{vol} . \%$.

13 The second optimisation predicts a lower temperature than that of the first due to the 14 lower concentration of lactose. For maximising the $\mathrm{CC}$ gas and the relative amount of $15 \mathrm{H}_{2}$ in the gas (Opt. 3), the temperature must be increased up to $586^{\circ} \mathrm{C}$. As a result a CC 16 gas of $88 \%$ and a proportion of $\mathrm{H}_{2}$ in the gas of 67 vol. $\%$ can be obtained. This increase 17 of $80{ }^{\circ} \mathrm{C}$ reduces the $\mathrm{CC}$ liq from 6 to $0 \%$ and the $\mathrm{CC}$ sol from 18 to $12 \%$. These 18 conditions not only produce a $\mathrm{H}_{2}$ rich gas from cheese whey, but also provide a carbon19 free liquid product that can be discharged to the environment without any further 20 treatment, thus helping to improve the economy and sustainability of the cheese 21 manufacturing companies.

23 An energy balance for the process was conducted for the third optimisation using Hysys

248.4 simulation software with a PRSV thermodynamic package. The input energy, 25 calculated as the sum of energy needed to heat the feed up to the reforming temperature 
1 and the energy needed for the steam reforming reaction, is $3555 \mathrm{~kJ} / \mathrm{kg}$ of solution. The

2 theoretical output energy, calculated as the energy recovered from the gas as it is cooled

3 from the reforming temperature to $25{ }^{\circ} \mathrm{C}$ (assuming water in liquid state), is $3338 \mathrm{~kJ} / \mathrm{kg}$

4 of solution. As a result, it is necessary to provide $217 \mathrm{~kJ} / \mathrm{kg}$ of solution for the process.

5 This energy can be theoretically generated by the combustion of $20 \%$ of the reforming

6 gas with the stoichiometric amount of air $(0.07 \mathrm{~kg}$ air $/ \mathrm{kg}$ solution $)$ and with the energy

7 recovered from the gas as it is cooled from the adiabatic combustion temperature (1632

$8{ }^{\circ} \mathrm{C}$ ) to $25^{\circ} \mathrm{C}$ (assuming water in liquid state). Figure 10 shows a schematic diagram of

9 this reforming-combustion process. Overall, with the combustion of $20 \%$ of the gas

10 produced in the process, $68 \%$ of the carbon present in the original feed can be

11 transformed into a rich hydrogen gas (67 vol.\%), with a global $\mathrm{H}_{2}$ yield of $16 \mathrm{~mol}$

$12 \mathrm{H}_{2} /$ mol lactose in a neutral energy process.

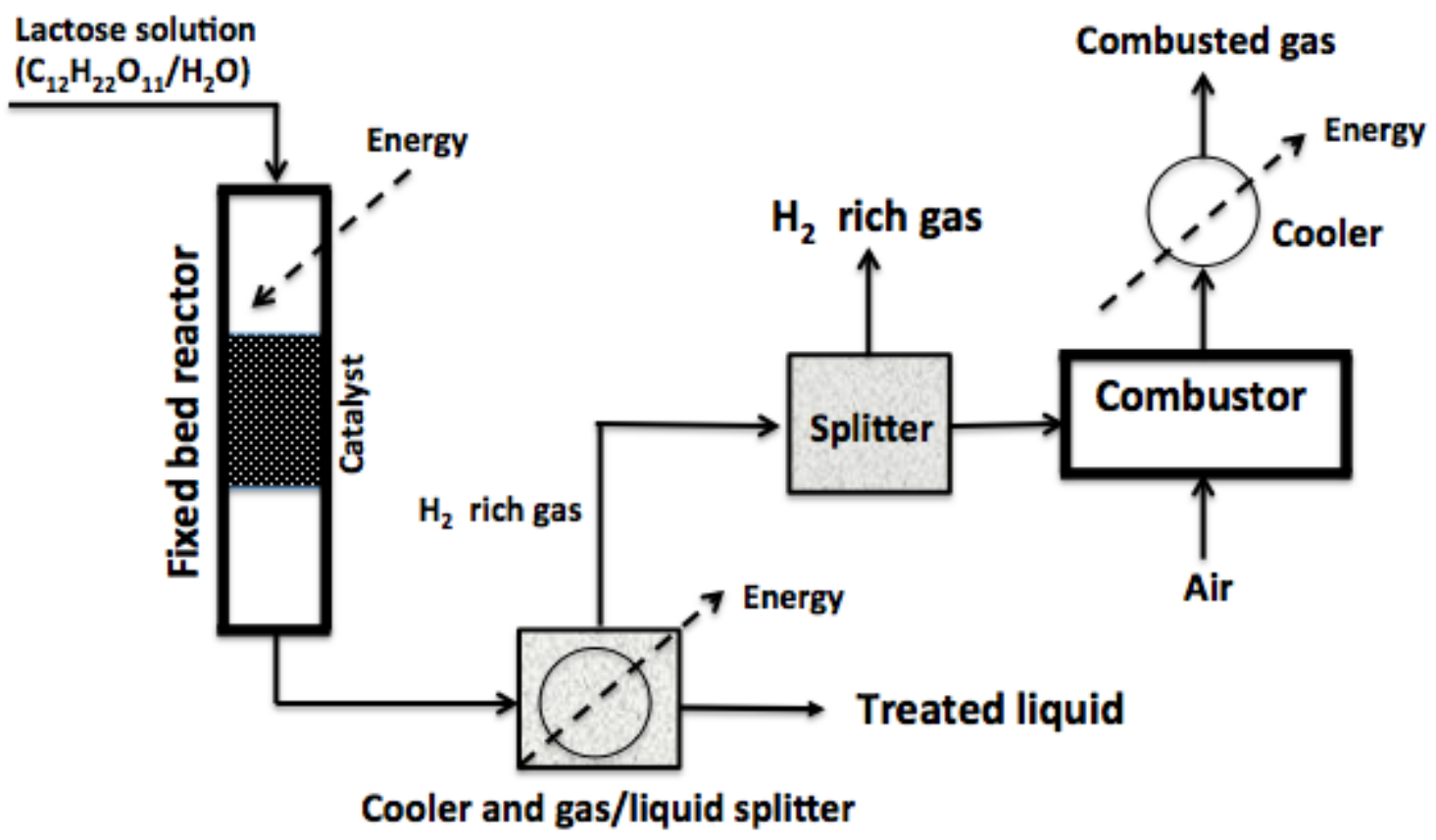

15 Figure 10. Schematic diagram of the reforming-combustion process 
1 To study a more realistic case, it has been considered that $5 \%$ of the energy recovered in

2 the coolers and produced by combustion is lost. In this case, considering an energy loss

3 of $5 \%$ in the burner and the subsequent cooler, the combustion of $41 \%$ of the reforming

4 gas would be required to provide the energy necessary for the process. The

5 stoichiometric amount of air and the adiabatic combustion temperature are $0.13 \mathrm{~kg}$

6 air/kg solution and $1606{ }^{\circ} \mathrm{C}$, respectively. Taking these heat losses into account, an

7 overall carbon conversion to gas of $52 \%$ and a global $\mathrm{H}_{2}$ yield of $12.5 \mathrm{~mol} \mathrm{H}_{2} / \mathrm{mol}$

8 lactose could be obtained from this valorisation-combustion process.

10 This $\mathrm{H}_{2}$ yield is close to the theoretical maximum of the process ( $24 \mathrm{~mol} \mathrm{H}_{2} / \mathrm{mol}$

11 lactose) and is higher than those obtained in anaerobic fermentation ( $4 \mathrm{~mol} \mathrm{H}_{2} / \mathrm{mol}$

12 lactose) or anaerobic fermentation plus photo-fermentation with L-malic acid (2-10 mol

$13 \mathrm{H}_{2} /$ mol lactose). In addition, the energy calculations indicate that catalytic steam

14 reforming is energetically feasible for energy and $\mathrm{H}_{2}$ production.

\section{4. Conclusions}

17 The catalytic steam reforming of lactose, the major organic constituent of cheese whey,

18 has been evaluated both theoretically and experimentally in a fixed bed reactor using a

19 Ni-based catalyst. The most important conclusions obtained from this preliminary study

20 for the valorisation of this waste stream obtained during the cheese making process are

21 summarised as follows.

22 1. This process enables the lactose present in cheese whey effluents to be transformed

23 into a rich $\mathrm{H}_{2}$ gas, reducing the amount of carbon present in the liquid effluent and

24 resulting in an almost carbon-free liquid stream under certain operating conditions. 
12 . The temperature and the concentration of lactose are the factors with the highest

2 influence on the thermodynamics of lactose steam reforming. A thermodynamic

3 optimum for $\mathrm{H}_{2}$ production is found to be at a temperature between 430 and $570{ }^{\circ} \mathrm{C}$ for

4 the whole range of lactose concentrations considered in this work (1-10 wt.\%).

5 3. The temperature, lactose concentration and $\mathrm{W} / \mathrm{m}_{\text {lactose }}$ ratio have a statistically

6 significant influence on the carbon conversions to gas, solid and liquid products as well

7 as on the composition of the gas and liquid phases. An increase in the temperature

8 augments the $\mathrm{CC}$ gas, due to the endothermic nature of the reforming process. In

9 addition, the temperature enhances the vaporisation of the feed and promotes the

10 gasification of the carbonaceous deposits derived from an incomplete vaporisation.

11 4. The gas phase was made up of a mixture of $\mathrm{H}_{2}$ (10-68 vol.\%), $\mathrm{CO}_{2}$ (24-63 vol.\%),

$12 \mathrm{CO}\left(1-28\right.$ vol.\%) and $\mathrm{CH}_{4}(0-1$ vol.\%). The temperature is the operating variable with

13 the greatest influence on the composition of the gas. An increase in the reforming

14 temperature increases the proportion of $\mathrm{H}_{2}$ and reduces the concentration of $\mathrm{CO}$ in the

15 gas. An increase in the $\mathrm{W} / \mathrm{m}_{\text {lactose }}$ ratio favours the reforming and the water gas shift

16 reactions. The effect of the concentration of lactose on the composition of the gas phase

17 depends on the temperature and $\mathrm{W} / \mathrm{m}_{\text {lactose }}$ ratio due to the coexistence and competition

18 of kinetic (vaporisation and reforming reaction rates) and thermodynamic effects.

19 5. The liquid phase is made up of a mixture of aldehydes, ketones, carboxylic acids,

20 sugars, furans, alcohols and phenols derived from the thermal decomposition of lactose.

21 This thermal decomposition involves competition between fragmentation and

22 condensation reactions.

23 6. The maximum CC gas (88\%) together with the highest proportion of $\mathrm{H}_{2}(67 \mathrm{vol} . \%)$ in

24 the gas, along with a carbon-free liquid stream when feeding a 5.5 wt.\% lactose solution

25 (typical of cheese whey), are achieved using a reforming temperature of $586{ }^{\circ} \mathrm{C}$ and 
1 employing a $\mathrm{W} / \mathrm{m}_{\text {lactose }}$ ratio of $16 \mathrm{~g}$ catalyst $\mathrm{min} / \mathrm{g}$ lactose. The combustion of $20 \%$ of

2 this reforming gas provides the energy necessary for the process. Considering the global

3 process (reforming and combustion) a rich hydrogen gas with a global $\mathrm{H}_{2}$ yield of 16

$4 \mathrm{~mol} \mathrm{H}_{2} / \mathrm{mol}$ lactose can be obtained. If heat losses are considered, the proportion of the

5 reforming gas needed for combustion increases up to $40 \%$, and the global $\mathrm{H}_{2}$ yield

6 decreases up to a value of $12.5 \mathrm{~mol} \mathrm{H}_{2} / \mathrm{mol}$ lactose.

7

8 Acknowledgements

9 The authors wish to express their gratitude to the Aragon Government (GPT group),

10 European Social Fund and Spanish MINECO (projects ENE2010-18985 and ENE2013-

11 41523-R) for providing financial support. In addition, Javier Remón Núñez would like

12 to express his gratitude to the Spanish MINECO for the FPI grant awarded (BES- 2011-

13 044856).

\section{References}

16 [1] F. Carvalho, A.R. Prazeres, J. Rivas. Cheese whey wastewater: characterization and 17 treatment. The Science of the Total Environment. 445-446 (2013) 385-96.

18 [2] R.R. de Souza, R. Bergamasco, S.C. da Costa, X. Feng, S.H.B. Faria, M.L.

19 Gimenes. Recovery and purification of lactose from whey. Chemical Engineering and

20 Processing: Process Intensification. 49 (2010) 1137-43.

21 [3] A.R. Prazeres, F. Carvalho, J. Rivas. Cheese whey management: a review. Journal 22 of Environmental Management. 110 (2012) 48-68.

23 [4] M.I.G. Siso. The biotechnological utilization of cheese whey: A review. Bioresource 24 Technology. 57 (1996) 1-11.

25 [5] O. Díaz, C.D. Pereira, A. Cobos. Functional properties of ovine whey protein

26 concentrates produced by membrane technology after clarification of cheese

27 manufacture by-products. Food Hydrocolloids. 18 (2004) 601-10.

28 [6] D. Misún, L. Curda, P. Jelen. Batch and continuous hydrolysis of ovine whey 29 proteins. Small Ruminant Research. 79 (2008) 51-6.

30 [7] G. Guven, A. Perendeci, A. Tanyolac. Electrochemical treatment of deproteinated

31 whey wastewater and optimization of treatment conditions with response surface

32 methodology. Journal of Hazardous Materials. 157 (2008) 69-78. 
[8] S. Ozmihci, F. Kargi. Ethanol production from cheese whey powder solution in a packed column bioreactor at different hydraulic residence times. Biochemical Engineering Journal. 42 (2008) 180-5.

4 [9] G. Vidal, A. Carvalho, R. Méndez, J.M. Lema. Influence of the content in fats and

5 proteins on the anaerobic biodegradability of dairy wastewaters. Bioresource

6 Technology. 74 (2000) 231-9.

7 [10] A.J. Mawson. Bioconversions for whey utilization and waste abatement.

8 Bioresource Technology. 47 (1994) 195-203.

9 [11] S. Sansonetti, S. Curcio, V. Calabrò, G. Iorio. Bio-ethanol production by

10 fermentation of ricotta cheese whey as an effective alternative non-vegetable source.

11 Biomass and Bioenergy. 33 (2009) 1687-92.

12 [12] J.J. Fitzpatrick, C. Murphy, F.M. Mota, T. Pauli. Impurity and cost considerations

13 for nutrient supplementation of whey permeate fermentations to produce lactic acid for

14 biodegradable plastics. International Dairy Journal. 13 (2003) 575-80.

15 [13] M.I. González, S. Álvarez, F. Riera, R. Álvarez. Economic evaluation of an

16 integrated process for lactic acid production from ultrafiltered whey. Journal of Food

17 Engineering. 80 (2007) 553-61.

18 [14] U. Kulozik, J. Wilde. Rapid lactic acid production at high cell concentrations in

19 whey ultrafiltrate by Lactobacillus helveticus. Enzyme and Microbial Technology. 24

20 (1999) 297-302.

21 [15] A.W. Schepers, J. Thibault, C. Lacroix. Continuous lactic acid production in whey

22 permeate/yeast extract medium with immobilized Lactobacillus helveticus in a two-

23 stage process: Model and experiments. Enzyme and Microbial Technology. 38 (2006)

$24 \quad 324-37$.

25 [16] A. Vasala, J. Panula, P. Neubauer. Efficient lactic acid production from high salt

26 containing dairy by-products by Lactobacillus salivarius ssp. salicinius with pre-

27 treatment by proteolytic microorganisms. Journal of Biotechnology. 117 (2005) 421-31.

28 [17] N. Azbar, F.T. Çetinkaya Dokgöz, T. Keskin, K.S. Korkmaz, H.M. Syed.

29 Continuous fermentative hydrogen production from cheese whey wastewater under

30 thermophilic anaerobic conditions. International Journal of Hydrogen Energy. 34 (2009)

31 7441-7.

32 [18] N. Venetsaneas, G. Antonopoulou, K. Stamatelatou, M. Kornaros, G. Lyberatos.

33 Using cheese whey for hydrogen and methane generation in a two-stage continuous

34 process with alternative $\mathrm{pH}$ controlling approaches. Bioresource Technology. 100

35 (2009) 3713-7.

36 [19] N. Azbar, F.T. Cetinkaya Dokgoz. The effect of dilution and 1-malic acid addition

37 on bio-hydrogen production with Rhodopseudomonas palustris from effluent of an

38 acidogenic anaerobic reactor. International Journal of Hydrogen Energy. 35 (2010)

39 5028-33.

40 [20] E. Castelló, C. García y Santos, T. Iglesias, G. Paolino, J. Wenzel, L. Borzacconi,

41 et al. Feasibility of biohydrogen production from cheese whey using a UASB reactor:

42 Links between microbial community and reactor performance. International Journal of

43 Hydrogen Energy. 34 (2009) 5674-82.

44 [21] M. Ferchichi, E. Crabbe, G.-H. Gil, W. Hintz, A. Almadidy. Influence of initial pH

45 on hydrogen production from cheese whey. Journal of Biotechnology. 120 (2005) 402-

469.

47 [22] G. Davila-Vazquez, F. Alatriste-Mondragón, A. de León-Rodríguez, E. Razo-

48 Flores. Fermentative hydrogen production in batch experiments using lactose, cheese

49 whey and glucose: Influence of initial substrate concentration and $\mathrm{pH}$. International

50 Journal of Hydrogen Energy. 33 (2008) 4989-97. 
[23] G. Davila-Vazquez, C.B. Cota-Navarro, L.M. Rosales-Colunga, A. de LeónRodríguez, E. Razo-Flores. Continuous biohydrogen production using cheese whey: Improving the hydrogen production rate. International Journal of Hydrogen Energy. 34 (2009) 4296-304. [24] L.M. Rosales-Colunga, E. Razo-Flores, L.G. Ordoñez, F. Alatriste-Mondragón, A. De León-Rodríguez. Hydrogen production by Escherichia coli Ahyca Alaci using cheese whey as substrate. International Journal of Hydrogen Energy. 35 (2010) 491-9. [25] P. Yang, R. Zhang, J. McGarvey, J. Benemann. Biohydrogen production from cheese processing wastewater by anaerobic fermentation using mixed microbial communities. International Journal of Hydrogen Energy. 32 (2007) 4761-71. [26] X. Song, Z. Guo. Technologies for direct production of flexible $\mathrm{H}_{2} / \mathrm{CO}$ synthesis gas. Energy Conversion and Management. 47 (2006) 560-9.

[27] J.A. Medrano, M. Oliva, J. Ruiz, L. Garcia, J. Arauzo. Catalytic steam reforming of acetic acid in a fluidized bed reactor with oxygen addition. International Journal of Hydrogen Energy. 33 (2008) 4387-96.

[28] J.A. Medrano, M. Oliva, J. Ruiz, L. Garcia, J. Arauzo. Hydrogen from aqueous fraction of biomass pyrolysis liquids by catalytic steam reforming in fluidized bed. Energy. 36 (2011) 2215-24.

[29] J. Remón, F. Broust, J. Valette, Y. Chhiti, I. Alava, A.R. Fernandez-Akarregi, et al. Production of a hydrogen-rich gas from fast pyrolysis bio-oils: Comparison between homogeneous and catalytic steam reforming routes. International Journal of Hydrogen Energy. 39 (2014) 171-82.

[30] J. Remón, J.A. Medrano, F. Bimbela, L. García, J. Arauzo. Ni/Al-Mg-O solids modified with $\mathrm{Co}$ or $\mathrm{Cu}$ for the catalytic steam reforming of bio-oil. Applied Catalysis B: Environmental. 132-133 (2013) 433-44.

[31] X. Hu, G. Lu. Investigation of the steam reforming of a series of model compounds derived from bio-oil for hydrogen production. Applied Catalysis B: Environmental. 88 (2009) 376-85.

[32] M. Marquevich, S. Czernik, E. Chornet, D. Montané. Hydrogen from Biomass: Steam Reforming of Model Compounds of Fast-Pyrolysis Oil. Energy \& Fuels. 13 (1999) 1160-6.

[33] H. Chen, Y. Ding, N.T. Cong, B. Dou, V. Dupont, M. Ghadiri, et al. A comparative study on hydrogen production from steam-glycerol reforming: thermodynamics and experimental. Renewable Energy. 36 (2011) 779-88.

[34] C. Wang, B. Dou, H. Chen, Y. Song, Y. Xu, X. Du, et al. Hydrogen production from steam reforming of glycerol by $\mathrm{Ni}-\mathrm{Mg}-\mathrm{Al}$ based catalysts in a fixed-bed reactor. Chemical Engineering Journal. 220 (2013) 133-42.

38 [35] B. Dou, Y. Song, C. Wang, H. Chen, Y. Xu. Hydrogen production from catalytic 39 steam reforming of biodiesel byproduct glycerol: Issues and challenges. Renewable and 40 Sustainable Energy Reviews. 30 (2014) 950-60.

41 [36] J. Remón, F. Broust, G. Volle, L. García, J. Arauzo. Hydrogen production from

42 pine and poplar bio-oils by catalytic steam reforming. Influence of the bio-oil

43 composition on the process. International Journal of Hydrogen Energy. 40 (2015) 559344608.

45 [37] A.M. Hilmen, D. Schanke, A. Holmen. TPR study of the mechanism of rhenium 46 promotion of alumina-supported cobalt Fischer-Tropsch catalysts. Catalysis Letters. 38 47 (1996) 143-7.

48 [38] B. Jongsomjit, J. Panpranot, J.G. Goodwin Jr. Co-Support Compound Formation in 49 Alumina-Supported Cobalt Catalysts. Journal of Catalysis. 204 (2001) 98-109. 
[39] A. Kogelbauer, J.G. Goodwin, R. Oukaci. Ruthenium promotion of $\mathrm{Co} / \mathrm{Al}_{2} \mathrm{O}_{3}$ Fischer-Tropsch catalysts. Journal of Catalysis. 160 (1996) 125-33.

[40] T.R. Carlson, J. Jae, Y.-C. Lin, G.A. Tompsett, G.W. Huber. Catalytic fast pyrolysis of glucose with HZSM-5: The combined homogeneous and heterogeneous reactions. Journal of Catalysis. 270 (2010) 110-24. [41] R.R. Davda, J.W. Shabaker, G.W. Huber, R.D. Cortright, J.A. Dumesic. A review of catalytic issues and process conditions for renewable hydrogen and alkanes by aqueous-phase reforming of oxygenated hydrocarbons over supported metal catalysts. Applied Catalysis B: Environmental. 56 (2005) 171-86.

10 [42] Y.-C. Lin. Catalytic valorization of glycerol to hydrogen and syngas. International 11 Journal of Hydrogen Energy. 38 (2013) 2678-700. [43] Z. Abu El-Rub, E.A. Bramer, G. Brem. Experimental comparison of biomass chars with other catalysts for tar reduction. Fuel. 87 (2008) 2243-52.

[44] N.B. Klinghoffer, M.J. Castaldi, A. Nzihou. Influence of char composition and inorganics on catalytic activity of char from biomass gasification. Fuel. 157 (2015) 3747.

[45] Z. Min, P. Yimsiri, M. Asadullah, S. Zhang, C.-Z. Li. Catalytic reforming of tar during gasification. Part II. Char as a catalyst or as a catalyst support for tar reforming. Fuel. 90 (2011) 2545-52.

[46] T.Y. Mun, J.O. Kim, J.W. Kim, J.S. Kim. Influence of operation conditions and additives on the development of producer gas and tar reduction in air gasification of construction woody wastes using a two-stage gasifier. Bioresource Technology. 102 (2011) 7196-203.

[47] T. Oike, S. Kudo, H. Yang, J. Tahara, H.-S. Kim, R. Koto, et al. Sequential Pyrolysis and Potassium-Catalyzed Steam-Oxygen Gasification of Woody Biomass in a Continuous Two-Stage Reactor. Energy \& Fuels. 28 (2014) 6407-18.

[48] N. Striūgas, K. Zakarauskas, G. Stravinskas, V. Grigaitienè. Comparison of steam reforming and partial oxidation of biomass pyrolysis tars over activated carbon derived from waste tire. Catalysis Today. 196 (2012) 67-74.

[49] D. Wang, W. Yuan, W. Ji. Char and char-supported nickel catalysts for secondary syngas cleanup and conditioning. Applied Energy. 88 (2011) 1656-63.

[50] R.P.B. Ramachandran, G. van Rossum, W.P.M. van Swaaij, S.R.A. Kersten. Evaporation of biomass fast pyrolysis oil: Evaluation of char formation. Environmental Progress \& Sustainable Energy. 28 (2009) 410-7.

[51] C. Wang, B. Dou, H. Chen, Y. Song, Y. Xu, X. Du, et al. Renewable hydrogen production from steam reforming of glycerol by $\mathrm{Ni}-\mathrm{Cu}-\mathrm{Al}, \mathrm{Ni}-\mathrm{Cu}-\mathrm{Mg}, \mathrm{Ni}-\mathrm{Mg}$ catalysts. International Journal of Hydrogen Energy. 38 (2013) 3562-71.

[52] M. Bertero, G. de la Puente, U. Sedran. Fuels from bio-oils: Bio-oil production from different residual sources, characterization and thermal conditioning. Fuel. 95 (2012) 263-71.

[53] M. Bertero, U. Sedran. Conversion of pine sawdust bio-oil (raw and thermally processed) over equilibrium FCC catalysts. Bioresource Technology. 135 (2013) 64451.

[54] Y. Wang, X. Hu, D. Mourant, Y. Song, L. Zhang, C. Lievens, et al. Evolution of aromatic structures during the reforming of bio-oil: Importance of the interactions among bio-oil components. Fuel. 111 (2013) 805-12.

[55] Y. Wang, D. Mourant, X. Hu, S. Zhang, C. Lievens, C.-Z. Li. Formation of coke during the pyrolysis of bio-oil. Fuel. 108 (2013) 439-44. 
1 [56] Q. Lu, X.-c. Yang, C.-q. Dong, Z.-f. Zhang, X.-m. Zhang, X.-f. Zhu. Influence of 2 pyrolysis temperature and time on the cellulose fast pyrolysis products: Analytical Py3 GC/MS study. Journal of Analytical and Applied Pyrolysis. 92 (2011) 430-8.

4 [57] F. Chambon, F. Rataboul, C. Pinel, A. Cabiac, E. Guillon, N. Essayem. Cellulose 5 hydrothermal conversion promoted by heterogeneous Brønsted and Lewis acids:

6 Remarkable efficiency of solid Lewis acids to produce lactic acid. Applied Catalysis B:

7 Environmental. 105 (2011) 171-81.

8 [58] D. Wang, D. Montané, E. Chornet. Catalytic steam reforming of biomass-derived 9 oxygenates: acetic acid and hydroxyacetaldehyde. Applied Catalysis A: General. 143 10 (1996) 245-70.

11 [59] S. Wang, X. Li, F. Zhang, Q. Cai, Y. Wang, Z. Luo. Bio-oil catalytic reforming 12 without steam addition: Application to hydrogen production and studies on its 13 mechanism. International Journal of Hydrogen Energy. 38 (2013) 16038-47. 